\title{
Private Equity Performance and Liquidity Risk
}

\author{
FRANCESCO FRANZONI ERIC NOWAK LUDOVIC PHALIPPOU*
}

September 5, 2011

\begin{abstract}
Private equity has traditionally been thought to provide diversification benefits. However, these benefits may be lower than anticipated as we find that private equity suffers from significant exposure to the same liquidity risk factor as public equity and other alternative asset classes. The unconditional liquidity risk premium is about $3 \%$ annually and, in a four factor model, the inclusion of this liquidity risk premium reduces alpha to zero. In addition, we provide evidence that the link between private equity returns and overall market liquidity occurs via a funding liquidity channel.
\end{abstract}

JEL classification: C51; G12; G23

Keywords: Private equity; Liquidity risk; Cost of capital

\footnotetext{
*Francesco Franzoni and Eric Nowak, University of Lugano and Swiss Finance Institute, via G. Buffi 13, Lugano, Switzerland. Ludovic Phalippou, University of Oxford, Said Business School, OX1 1HP, Oxford, UK. Emails: francesco.franzoni@usi.ch, eric.nowak@usi.ch, and ludovic.phalippou@ox.ac.co.uk. We are especially grateful to the editor, Cam Harvey, and anonymous associate editor and referee for greatly contributing to the final version of the paper. We are also grateful to Philipp Krohmer and Daniel Schmidt of CEPRES GmbH for their support and giving us access to their database. We thank Viral Acharya, Fernando Anjos, Giovanni Barone-Adesi, Alessandro Beber, Dion Bongaerts, Andrea Caprara, Joost Driessen, Frank de Jong, Patrick Gagliardini, Tim Jenkinson, Christian Julliard, Marcin Kacperczyk, Aditya Kaul, Laurence Lescourret, Hanno Lustig, Roni Michaely, Adair Morse, Tarun Ramadorai, Christian Rauch, Diego Ronchetti, Elvira Sojli, Per Stromberg, Fabio Trojani, Marno Verbeek, Anette Vissing-Jorgensen, and conference participants at ESSEC, Erasmus university, ISCTE, the CEPR Symposium in Gerzensee, the German Finance Association Meeting, Argentum PE conference, and seminar participants at the Universities of Amsterdam, Oxford and Tilburg for helpful comments. We thank Alexander Eisele and Vera Baranouskaya for excellent research assistance. This project is financially supported by NETSPAR, NCCR-FINRISK, and RICAFE II (European Commission contract no. 028942.)
} 
Investing in private equity is among the preferred choices for long-term investors, such as endowments and pension funds, who seek to diversify their portfolios. Such long term investors are clearly the best suited for holding an illiquid asset (i.e. one that cannot be readily traded) such as private equity. The diversification benefits of private equity, however, have not been widely documented. In particular, an issue which has not been addressed so far, is whether private equity performance, like that of other asset classes, is affected by liquidity risk (i.e. it co-moves with unexpected changes in overall market liquidity). ${ }^{1}$ The primary goal of this paper is to quantity liquidity risk in private equity. In addition, the estimation of a factor model that includes the liquidity risk factor allows us to compute the cost of capital for this asset class and test whether it is efficiently priced.

We use a unique and comprehensive dataset containing the exact cash flows generated by a large number of liquidated private equity investments. In order to clarify from the start the peculiar structure of our data, Table 1 shows a typical cash flow stream. There is an initial negative cash flow (the investment) followed by two positive cash flows (an intermediate distribution and the final dividend corresponding to the divestment). Note that we do not have intermediate valuations for the investment. So, there is no time series of returns, which precludes the use of the usual time-series regressions to estimate risk exposures. In such a context, as in Cochrane (2005), Korteweg and Sorensen (2010) and Driessen, Lin, and Phalippou (2011), we exploit variation in returns across investments to estimate the risk loadings and abnormal performance of the asset class.

We fit the four-factor model of Pástor and Stambaugh (2003) to the data and find a significant beta on the liquidity risk factor (0.64), on the market factor (1.3), and on bookto-market factor (1.0), but not on the size factor. The exposure to these factors brings the alpha of this asset class to zero.

Importantly, the liquidity risk premium is about $3 \%$ annually, which implies a roughly $10 \%$ discount in the valuation of the typical investment (see Table 1$).^{2}$ We also note that a liquidity risk beta of 0.64 exceeds the corresponding estimate for the large majority (86\%) of traded stocks.

These results suggest that private equity is significantly exposed to the same liquidity 
risk factor as public equity and other asset classes. The diversification gains that can originate from private equity may thus be lower than previously thought given the exposure to liquidity risk.

Prompted by the finding of a significant loading on liquidity risk, we study the economic channel that relates private equity returns to market liquidity. We conjecture that due to their high leverage, private equity investments are sensitive to the capital constraints faced by the providers of debt to private equity, who are primarily banks and hedge funds. Brunnermeier and Pedersen (2009) develop a theory in which the availability of capital which they term funding liquidity - is positively related to market liquidity. In our context, their argument suggests that times of low market liquidity are likely to coincide with times when private equity managers may find it difficult to refinance their investments. In these periods, they may be forced to liquidate the investments or to accept higher borrowing costs, which in turn translates into lower returns for this asset class. Then, we conjecture that the link between private equity returns and market liquidity occurs via a funding liquidity channel.

Empirically, we proxy for the evolution in funding liquidity with changes in the credit standards as reported in the Federal Reserve's Senior Loan Officer Survey. This survey asks loan officers at main banks whether they tightened or loosened their lending standards relative to the previous quarter. Axelson, Jenkinson, Strömberg, and Weisbach (2010) argue that, in the private equity context, "this measure captures non-price aspects of credit market conditions, such as debt covenants and quantity constraints." They find this measure to be strongly related to the amount of leverage used to finance private equity investments. In addition, Lown and Morgan (2006) present evidence that this variable strongly correlates with bank loans and is more important than interest rates in explaining loan volume. ${ }^{3}$

Turning to the empirical evidence on this channel, we first document a strong relation between private equity investment returns and the average innovation in market liquidity (as measured by Pástor and Stambaugh (2003)) during the investment's life. The average difference in performance for investments at the extreme deciles of market liquidity innovations is a striking $46 \%$ per year. This result is confirmed in a multiple regression set- 
ting, in which we control for investment characteristics and macroeconomic variables (credit spreads, M\&A cycles, growth in industrial production, change in stock market volatility).

Next, we test our conjecture that funding liquidity is the link between these two variables. We first show that returns are significantly related to the tightening in credit standards. A one-standard deviation increase in this measure of the deterioration in funding liquidity decreases the annual return by $19.5 \%$. Second, when including both the measure of funding liquidity and that of market liquidity, we observe that funding liquidity absorbs half of the market liquidity effect. In addition, we conduct a time-series test using the aggregate cash flows of all the private equity investments each month. Consistent with the cross-sectional evidence, we find that net cash flows (dividends minus investments) are lower at times of tightening in credit standards and at times of worsening liquidity conditions.

We find these results important for two related reasons. First, they improve our understanding of the economic channel underlying the relationship between private equity returns and market liquidity. Market liquidity is found to be closely related to a measure of funding liquidity, which in turn is a determinant of the ease of refinancing for leveraged deals as shown by Axelson, Jenkinson, Strömberg, and Weisbach (2010). Second, these results provide empirical support for the theory of Brunnermeier and Pedersen (2009) relating funding liquidity to market liquidity. Our empirical evidence shows that there is indeed a negative relationship between a dry-up in funding liquidity (the tightening in credit standards) and innovations in market liquidity (the Pástor and Stambaugh measure).

The paper continues as follows. Section I describes the data and the liquidity measures. Section II estimates different asset pricing models and computes the cost of capital and alpha for private equity. Section III relates private equity performance to market risk, funding liquidity, macroeconomic variables, and investment characteristics. Section IV discusses the implications of our results and concludes.

\section{The data}

In this section, we first detail how the data are collected, then document the coverage of our dataset relative to available commercial datasets, and gauge its representativeness in 
terms of performance. We next describe how we measure returns in our context, and finally provide some descriptive statistics of returns.

\section{A. Data source}

The dataset is provided by the Center for Private Equity Research (CEPRES GmbH), a currently independent advisory firm established in 2001 as a joint-venture between VCM Capital Management (part of the Deutsche Bank Group) and the University of Frankfurt. The unique feature of these data is the information on the monthly cash flows generated by private equity investments.

CEPRES obtains data from private equity houses who make use of a service called "The Private Equity Analyzer". ${ }^{4}$ Participating private equity houses report cash flows (before fees) generated for each investment they have made in the past. In return, the firms receive statistics such as risk-adjusted performance measures. These statistics are then used internally for various purposes such as bonus payments, or risk management (e.g. to comply with Solvency II). CEPRES does not benchmark private equity houses to peer groups; this improves data accuracy and representativeness, as it eliminates incentives to manipulate cash flows or cherry-pick past investments.

CEPRES may also be hired as an advisor. In such cases, it may receive data on the past performance of private equity houses. If permitted by the contractual agreement, CEPRES can add these track records to its database. If a track record is already in the Private Equity Analyzer database, then CEPRES systematically cross-checks that the data are accurate.

Earlier versions of this dataset have been used in previous studies. A subset covering mainly venture capital investments is used by Cumming, Schmidt, and Walz (2010), Cumming and Walz (2010) and Krohmer, Lauterbach, and Calanog (2009). For this study, CEPRES granted us access to all liquidated buyout investments in their database as of December 2007. Note that we use the wording buyout investments and private equity investments interchangeably. The earliest investment in our sample starts in 1975 and the most recent in 2006. In total, we have 4,403 investments.

We thus have access to a comprehensive and accurate panel of anonymous cash-flow 
streams generated by private equity investments. This enables us to construct precise measures of the investment performance and aggregate liquidity conditions over the investment's life, which is essential for estimating the relation between performance and liquidity risk. ${ }^{5}$

\section{B. Data coverage and representativeness}

To gauge coverage, we benchmark CEPRES to Standard \& Poor's Capital IQ database. Capital IQ is now often perceived as the most comprehensive dataset at the investment level (Bernstein, Lerner, Sorensen, and Strömberg (2010) and Strömberg (2007)). Table II shows that CEPRES has a total of 7,198 buyout investments between 1975 and 2006 versus 14,011 in Capital IQ, i.e., 51\%. During the early years, however, the coverage of CEPRES and Capital IQ is remarkably similar. From 1975 to 1994, CEPRES has slightly more investments than Capital IQ. After the mid-1990s, the number of investments in Capital IQ increases exponentially, while the rise is less pronounced for CEPRES. Note that, as mentioned above, we only use data on liquidated buyout investments. Because investments are held for 4 years on average, the pre-2002 coverage is more informative. Table II shows that for the period 1975-1999, CEPRES coverage is 85\% of Capital IQ. Benchmarking

Table II here performance in private equity is more difficult. The majority of previous studies have used Thomson Venture Economics, and private equity house performance is measured by a success ratio (the fraction of investments exited via IPO or M\&A over the total number of investments). ${ }^{6}$

Results are displayed in Table III. The success ratio is similarly distributed for the two datasets but the CEPRES dataset appears to contain firms that are slightly above average performance-wise. We also note that $10 \%$ of the investments in our dataset are bankrupt, which is similar to the rate reported by Strömberg (2007) for the Capital IQ dataset.

\section{Performance Measures}

As mentioned in the introduction, our data contain the series of cash flows generated by a given private equity investment. We begin by converting all the cash flows into US dollars. We note that this hardly changes performance. The correlation between performance 
in original currency and performance in US dollars is $99.8 \%$. This is probably because investments last only four years on average, hence currency changes do not greatly affect performance. In addition, about half of the cash flows are already in US dollars.

To measure investment performance, we use a Modified Internal Rate of Return (MIRR). MIRR measures the geometric average return for an investor who deposits dividends $\left(D_{t}\right)$ into, and draws her money for intermediate investments $\left(I_{t}\right)$ from, an account that earns an interest rate $x_{t}$ for each $t=1, \ldots, T$, where $T$ is the number of periods in the investment's life. The investment MIRR is defined as follows:

$$
\begin{aligned}
(1+M I R R)^{T} & =\frac{D_{1} \prod_{t=1}^{T-1}\left(1+x_{t}\right)+D_{2} \prod_{t=2}^{T-1}\left(1+x_{t}\right)+\cdots+D_{T-1}\left(1+x_{T-1}\right)+D_{T}}{I_{0}+\frac{I_{1}}{\left(1+x_{0}\right)}+\frac{I_{2}}{\prod_{t=0}^{1}\left(1+x_{t}\right)}+\cdots+\frac{I_{T}}{\prod_{t=0}^{T-1}\left(1+x_{t}\right)}} \\
& =\frac{F V\left(\operatorname{Div}, x_{t}\right)}{P V\left(\operatorname{Inv}, x_{t}\right)}
\end{aligned}
$$

where $F V\left(\cdot, x_{t}\right)$ and $P V\left(\cdot, x_{t}\right)$ respectively denote the forward and present value of a stream of cash flows computed using the discount rate $x_{t}$. Note that when no cash is returned to investors (that is, the dividends are all zero), the MIRR equals $-100 \%$.

We now give a numerical example of MIRR construction and its sensitivity to the reinvestment assumption. To do so we use the typical cash flow pattern shown in the introduction (Table I) and assume a constant reinvestment rate of $5 \%$ per semester. The final value of the dividends is:

$$
F V(\operatorname{Inv}, 5 \%)=50\left(1.05^{3}\right)+150=208
$$

The annualized MIRR is thus:

$$
M I R R=\left(\frac{208}{100}\right)^{1 / 4}-1=20 \%
$$

If we use a reinvestment rate of $0 \%$, the MIRR would be $19 \%$. Hence, the sensitivity of MIRR to the reinvestment assumption seems minor in our data. This is due to the 
relatively short life of the investments and the relatively small size of intermediate cash flows. In the analysis that follows, we use the $\mathrm{S} \& \mathrm{P} 500$ index as a reinvestment rate. This reinvestment assumption should capture the fact that private equity investors tend to have highly-diversified portfolios. We also computed the MIRR of each investment using the risk-free rate as the reinvestment rate and found a correlation coefficient of $99 \%$ between the two MIRRs.

\section{Descriptive statistics - Performance}

To provide aggregate performance figures, we group investments by their starting year and countries of location. Next, we sum the cash flows of all the investments in the group month by month. Finally, we compute the MIRR of each (pooled) cash flow stream. We thus replicate the rate of return of a buy-and-hold investor who selects all the investments of a certain country/region over a certain time period.

Table IV - Panel A shows the results. Overall, we find little difference across countries/regions and across time. Returns are highest for Europe (ex-UK) in the second half of the 1990s at 25\% annually, but returns in Europe were low in the first half of the 1990s at $14 \%$ annually. Returns are stable over time in the US, except for more recent years when they drop to $13 \%$. An investor buying all the investments in our sample would have earned $19 \%$ annually. The carried interest payable with such a return is about $4 \%$ and management fees on invested capital are at least $3 \%{ }^{7}$ Hence, after fees, this performance figure is at most $12 \%$, which is similar to the return documented by Kaplan and Schoar (2005) for net-of-fees (fund level) returns. This further demonstrates that our data are similar performance-wise to those used in previous research.

Table IV - Panel B shows that our observations are almost evenly distributed across regions: US (37\%), UK (29\%) and the rest of Europe (25\%).

Table IV here

\section{The liquidity risk premium in private equity returns}

As pointed out by Acharya and Pedersen (2005), among others, liquidity varies over time and displays commonality across securities and asset classes. Recent theoretical and 
empirical research suggests that this commonality in liquidity is a priced risk factor (liquidity risk). Pástor and Stambaugh (2003) propose a four-factor asset pricing model which includes liquidity risk. If we assume that the public and private equity markets are integrated then this asset pricing model and its corresponding pricing kernel can be applied to private equity to evaluate its cost of capital, which is naturally an important question for such a large asset class. In addition, the finding of a significant loading on the liquidity risk factor would cast a different light on the diversification benefits of private equity.

In this section, we begin by detailing our methodology to estimate a factor model for private equity returns. Next, we provide the estimates of the risk exposures, the alpha, and the resulting cost of capital. In the Internet Appendix, we extend the analysis to time-varying factor loadings and risk premia.

\section{A. Methodology}

\section{A.1. The estimation of risk exposures}

Because private equity investments are not continuously traded, we cannot compute a time-series of returns and use a traditional time-series approach to estimate risk exposures. Instead, we have cash flow streams for a cross-section of investments that we use to compute rates of returns, as described in Section I. This cross-sectional data structure fits into the approach developed by Cochrane (2005), which we adjust to our context. ${ }^{8}$

To start from the simplest case, let us assume that the cash flows of each project $i$ consist of an initial investment, $V_{0}^{i}$, and a final dividend, $V_{T_{i}}^{i}$, which is paid at date $T_{i}$. Following Cochrane (2005), we assume that one-period returns are log-normal and exhibit a linear factor structure (in logarithm)

$$
\ln R_{t+1}^{i}=\ln \frac{V_{t+1}^{i}}{V_{t}^{i}}=\gamma+\ln R_{t+1}^{f}+\delta^{\prime} f_{t+1}+\varepsilon_{t+1}^{i},
$$

where $\gamma$ is a constant, $R^{f}$ is the gross risk-free rate, $f_{t+1}$ is a vector of $k$ risk factors (e.g. the four factors of Pástor and Stambaugh (2003)), $\delta$ is a $k$-vector of risk factor loadings, and $\varepsilon_{t+1}^{i}$ is normal with mean zero and variance $\sigma^{2}$ and is independent of the risk factors. ${ }^{9}$ 
Given equation (2), the natural logarithm of the (gross) geometric average return on the investment $\left(R_{g}^{i}\right)$ is given by

$$
\ln \left(R_{g}^{i}\right)=\frac{1}{T_{i}} \ln \frac{V_{T}^{i}}{V_{0}^{i}}=\gamma+\frac{1}{T_{i}} \sum^{T_{i}} \ln R_{t+1}^{f}+\delta^{\prime} \frac{1}{T_{i}} \sum^{T_{i}} f_{t+1}+\frac{1}{T_{i}} \sum^{T_{i}} \varepsilon_{t+1}^{i} .
$$

The variance of the error term in equation (3) is $\frac{1}{T_{i}} \sigma^{2}$. To eliminate this source of heteroskedasticity, we multiply each side of equation (3) by $\sqrt{T_{i}}$

$$
\sqrt{T_{i}} \ln \left(R_{g}^{i}\right)=\gamma \sqrt{T_{i}}+\frac{1}{\sqrt{T_{i}}} \sum^{T_{i}} \ln R_{t+1}^{f}+\delta^{\prime} \frac{1}{\sqrt{T_{i}}} \sum^{T_{i}} f_{t+1}+\frac{1}{\sqrt{T_{i}}} \sum^{T_{i}} \varepsilon_{t+1}^{i} .
$$

This is a GLS transformation that we can perform because we know the form of heteroskedasticity. ${ }^{10}$ Equation (4) is the specification that we bring to the data. Notice that the right-hand side is linear in the parameters of interest. We can therefore simply apply a standard OLS regression. The dependent variable is the scaled natural logarithm of gross returns. The explanatory variables are the time-series averages of the risk factors during the investment's life (multiplied by $\sqrt{T_{i}}$ ) and the square root of the investment duration. Because this equation does not include a constant, the values of the R-squared from the OLS estimation are not meaningful and we do not report them. In the tables, however, we report the estimate of $\gamma$ and we label it 'Constant' for simplicity.

Because the parameters in equation (2) pertain to the logarithm of returns, we need to derive expressions for alpha and factor loadings for the level of returns. In other words, we need to convert $(\gamma, \delta)$ from equation (2) into the familiar $(\alpha, \beta)$, which are defined by the equation

$$
E\left(R_{t+1}^{i}\right)=R_{t+1}^{f}+\alpha+\beta^{\prime} E\left(f_{t+1}\right)
$$

In the Internet Appendix, we show that the formulas for conversion from the parameters in the log of returns to the parameters in the level of returns are

$$
\begin{aligned}
\beta & =R_{f} \delta e^{\gamma+\delta^{\prime} \mu_{F}+\frac{1}{2} \delta^{\prime} \sigma_{F}^{2} \delta+\frac{1}{2} \sigma^{2}} \\
\alpha & =R_{f}\left(e^{\gamma+\delta^{\prime} \mu_{F}+\frac{1}{2} \delta^{\prime} \sigma_{F}^{2} \delta+\frac{1}{2} \sigma^{2}}\left(1-\delta^{\prime} \mu_{F}\right)-1\right)
\end{aligned}
$$


where $\mu_{F}$ is the $k$-vector of factor means and $\sigma_{F}^{2}$ is the $k \times k$ variance-covariance matrix of the factors. Because $\beta$ turns out to be quite close to $\delta$, we only report the latter in our empirical results.

The approach described above is motivated by the specific structure of the data. As we do not observe periodic valuations of the investment, we cannot construct a time-series of investment returns $R_{t+1}^{i}$. Instead, we observe the investment cash flows, which allow us to construct a summary measure of performance over the investment's life, that is, the geometric average return $R_{g}^{i}$. This explains why, in equation (4), we relate the average investment return to the average factor realization over the investment's life (with a correction for heteroskedasticity).

This approach amounts to considering each investment as a separate realization of the returns on the asset class, then the variation in returns across investments is used to estimate the risk loadings and the abnormal performance of the asset class. This cross-sectional approach for non-traded assets is essentially the same as in Cochrane (2005), Korteweg and Sorensen (2010) and Driessen, Lin, and Phalippou (2011). Like in these papers, the identification comes from investments that are realized over partly non-overlapping time periods.

\section{A.2. Forming portfolios}

To measure the geometric return in equation (4), we use the investment's MIRR (see previous section for calculation details) and we need to deal with three issues. First, the logarithm of MIRR is not defined for $10 \%$ of the investments (those with a return of $-100 \%$ ). Second, as it is well-known in the empirical literature on stock returns, the high idiosyncratic risk of individual investments may induce substantial noise in risk estimates. Third, we use the assumption of normality of log-returns in order to derive alpha and betas, but the distribution of individual investment returns fails a D'Agostino, Belanger, and D'Agostino Jr. (1990) chi-squared normality test. Figure 1 shows the histogram of MIRRs and it is clear that the probability mass on the tails of the distribution, especially on the left one, explains the rejection of normality. To get around these three issues, we adopt the typical Figure 1 here 
approach in the Asset Pricing literature and group individual investments into portfolios. ${ }^{11}$ As mentioned above, the statistical identification comes from observing investment returns at different moments in time. Thus, a natural choice is to group together investments that start at the same date (at the monthly frequency). To ensure that portfolios are sufficiently diversified, we require a minimum of twenty investments per portfolio. If the number of investments starting in the same month is below this minimum, we include in the portfolio investments that are started the next month, and continue until the number of investments is at least twenty. ${ }^{12}$ Portfolio cash flow streams are obtained by summing the cash flows of the individual investments each month. Finally, we compute the MIRR of each portfolio.

By grouping investments based on their starting dates, we reduce idiosyncratic risk and preserve sufficient dispersion in the explanatory variables. In addition, when we form portfolios, we obtain a better-behaved distribution of returns and the normality assumption is not rejected ( $\mathrm{p}$-value is 0.44 ). Finally, we do not observe any portfolios with MIRR of $-100 \%$, meaning that the logarithm of the MIRR is always defined. We can thus estimate equation (4) by OLS at the portfolio level.

\section{B. Empirical estimates of risk exposures and alpha}

\section{B.1. The factor models}

We build up our estimate of the risk premium for private equity moving from the simplest model to a four-factor model that includes liquidity risk. We start with the CAPM, which is the model that Cochrane (2005) estimates for venture capital. Then, recognizing that private equity investments tend to be made predominantly in value companies, we consider the Fama and French (1993) three-factor model. Finally, we augment the threefactor model with the Pástor and Stambaugh (2003) traded liquidity factor. This factor is equal to the return on a portfolio that goes long the tenth liquidity-beta-decile portfolio and short the first liquidity-beta-decile portfolio. Liquidity betas are obtained by regressing individual stock returns on innovations in aggregated liquidity; and aggregate liquidity is the sum of stock-level OLS slopes of daily returns on signed daily trading volume within a given month. 
Assuming that markets are integrated, or more specifically that there is a unique pricing kernel for private and public equity, allows us to compute the prices of risk for the four factors from their realizations in the public equity market. Table V presents the correlation and distribution of these factors during our sample time period (October 1975 to December 2007). In particular, it shows the time-series mean for each factor. We use these means as estimates of the factor risk premia to computate the cost of capital. Multiplying the values in Table $\mathrm{V}$ by twelve, the liquidity premium is $4.5 \%$ annually. The market risk premium is 7.5\% annually. The HML and SMB premia are $4.9 \%$ and $2.9 \%$ annually, respectively. The (unreported) risk-free rate is $5.8 \%$ annually.

\section{B.2. Empirical results}

Panel A of Table VI reports the estimates of equation (4) for each of the factor models. In the first specification, the estimate of the CAPM beta is close to one and statistically significant. This number is consistent with the choice of Kaplan and Schoar (2005) to measure private equity performance by a public market equivalent with a beta of one. The second column in Panel A reveals that, after accounting for the other Fama and French (1993) factors, the loading on the market increases. This is due to the fact that private equity investments load positively and significantly on value stock returns and that HML and the market factor are negatively correlated in this sample. The loading on SMB is positive, but not statistically different from zero.

Finally, the last column in Panel A reports the estimates of the model including liquidity risk. The liquidity beta is about 0.64 and statistically significant at the $1 \%$ level. We also note that the slope on HML increases, suggesting that in the previous model the importance of HML is mitigated by the negative correlation between HML and the liquidity factor.

For each of the factor models, Panel B of Table VI reports the total risk premium, the cost of capital, and alpha estimates that result from transforming the model in logs to the model in levels according to equations (5) and (6). Each estimated factor risk premium is the product of the estimated factor loading times the average realization of the factor in the sample (described in the previous sub-section). 
The first line shows the sum of all the risk premia for each factor model. It varies from $7.3 \%$ with the CAPM to about $18 \%$ with the four factor model. The cost of capital is the sum of the risk-free rate and the total risk premium. The average risk-free rate in the sample is fairly high (especially compared to current levels). It makes the cost of capital higher by about $6 \%$ for all the factor models.

Finally, we present estimates of alpha. Alpha can be interpreted as the portion of expected returns that is not explained by the chosen asset pricing model. The CAPM leaves unexplained a high $9.3 \%$ of expected returns. In the second column, once the risk premia on the book-to-market factor and size factor are taken into account, the alpha drops to about $3.1 \%$ which is still economically (although not statistically) significant. In the model with liquidity risk (third column of Panel B), the premia on the four factors entirely account for average private equity returns. The alpha is virtually zero, both economically and statistically, while the risk premium and the cost of capital are about $18 \%$ and $24 \%$ per year, respectively. ${ }^{13}$ The liquidity risk premium thus appears to be an essential component to fully account for average private equity returns. ${ }^{14}$

\section{B.3. Economic significance}

Implications for company valuation. In the total risk premium, we note that the lion's share belongs to the market risk premium (10\%). The book-to-market premium is $5.2 \%$, while the size premium is insignificant. The liquidity risk premium amounts to a statistically significant $2.9 \%$ per year.

A simple way to assess the economic significance of a liquidity risk premium for private equity is to use the representative investment cash-flow pattern shown in Table I and value this investment using either a $15 \%$ discount rate or an $18 \%$ discount rate. The present values of this representative investment under the two alternative assumptions are 119 and 108 respectively, or a $10 \%$ difference. This simple algebra reveals that even a $3 \%$ liquidity premium has important economic implications when valuing investments. In addition, in the Internet Appendix, we use a conditional asset pricing framework and find that, in some periods, the liquidity risk premium well exceeds the unconditional value of $3 \%$. 
Comparing public equity and private equity liquidity risk exposures. It is also interesting to relate our estimate of liquidity risk for private equity to that for public equity. To do so, we simply compute the liquidity beta of all the stocks in CRSP with a standard time-series regression between January 1966 and December 2008 using the Pástor and Stambaugh (2003) four-factor model. We sort all the stocks by their loading on the liquidity factor and show the resulting histogram in Figure 2. The private equity liquidity beta of 0.638 corresponds to the 86 th percentile of the beta distribution for publicly listed equities (as shown by the vertical line in Figure 2). This result indicates that the liquidity risk in private equity is high compared to that of most publicly-traded companies. ${ }^{15}$

\section{The source of liquidity risk in private equity}

The factor model estimation in Section II shows that a liquidity risk factor is a significant determinant of private equity returns. The premium due to liquidity risk accounts for the abnormal performance of this asset class and is an important component of the cost of capital.

In this section, we set out to identify the channel that links variation in aggregate liquidity to private equity performance. First, we develop our main hypothesis. Second, we test it empirically using the cross-section of investment return data. Third, we provide consistent evidence from a time-series test.

\section{A. Hypothesis development}

The Pástor and Stambaugh (2003) traded liquidity factor that we use in Section II is based on a measure of stock market liquidity. One naturally wonders why private equity returns are related to the liquidity of public equity markets. Our hypothesis is based on two complementary arguments.

The first argument is provided by Brunnermeier and Pedersen (2009). They postulate a relation between market liquidity and funding liquidity, where funding liquidity is the availability of trading capital for investors. For our purposes, the focus is on banks and hedge funds which are the main providers of finance to private equity companies. Brun- 
nermeier and Pedersen (2009)'s theory suggests that times of low funding liquidity are also characterized by poor market liquidity. In their mechanism, labeled a liquidity spiral, a negative shock to investors' trading capital triggers margin calls and forced liquidations which, in turn, reduce market liquidity and exacerbate the initial trading losses. Consequently, poor market liquidity conditions, captured by the Pástor and Stambaugh (2003) factor, may reflect a dry-up in funding liquidity.

The second argument is that shocks to funding liquidity may be related to the return of private equity companies. One crucial characteristic of private equity investments, which distinguishes them from investments in public companies, is their higher leverage (e.g. Axelson, Strömberg, and Weisbach (2009)). The fact that these loans need to be refinanced or renegotiated (e.g., following a breach of covenants) makes private equity investments sensitive to the availability of capital of the debt providers (Axelson, Jenkinson, Strömberg, and Weisbach (2010), Kaplan and Strömberg (2009)). The providers of debt finance to private equity are mainly banks and hedge funds and certainly exposed to variations in funding liquidity of the type described by Brunnermeier and Pedersen (2009). At times of low liquidity, private equity houses may thus find it difficult to refinance their companies and may be forced to liquidate the investments or need to accept higher financing costs. This argument relates the returns of private equity companies to funding liquidity. ${ }^{16}$

These two arguments taken together are therefore suggesting that private equity returns correlate with market liquidity through the refinancing risk channel. In other words, the observed link between private equity returns and market liquidity results from the dependence of private equity performance on the availability of the capital to debt providers (funding liquidity) and from the link between funding liquidity and market liquidity.

In order to bring this conjecture to the data, we need to find a proxy for funding liquidity that is especially relevant for private equity. Axelson, Strömberg, and Weisbach (2009) propose the 'Senior Loan Officer Opinion Survey on Bank Lending Practices' as an indicator of the credit availability for private equity investments. The survey asks loan officers whether they tightened or loosened their lending standards relative to the previous quarter. Axelson, Jenkinson, Strömberg, and Weisbach (2010) argue that "this measure 
captures non-price aspects of credit market conditions, such as debt covenants and quantity constraints." They find this index to be strongly related to the amount of leverage used to finance private equity investments. Also, Lown and Morgan (2006) present evidence that this variable strongly correlates with bank loan changes and is more important than interest rates in explaining loan volume. Leary (2008) uses this measure to proxy for loan supply. He finds that it helps to explain differences in leverage between firms with and without bond market access. The tightening in credit standards has thus the double advantage of having been used and advocated in a private equity context and having strong empirical support. We therefore expect it to be a potentially accurate instrument to measure funding liquidity.

Given the arguments above, we conjecture that the tightening in credit standards is negatively related to private equity performance as a manifestation of the refinancing risk channel. Furthermore, we postulate that the observed relation between private equity returns and the Pástor and Stambaugh (2003) measure results from the link between funding liquidity and market liquidity. Hence, our chosen measure for the evolution in funding liquidity (the tightening in credit standards) should explain empirically part of the negative relation between private equity returns and market liquidity.

\section{B. Cross-sectional evidence}

In this sub-section, we empirically test the above conjecture using the cross-section of individual investments.

\section{B.1. Main results}

We first need to verify that, consistent with the finding of liquidity being a priced factor, unexpected market liquidity shocks are correlated with contemporaneous return. A measure of unexpected market liquidity shocks is provided by Pástor and Stambaugh (2003) and that is the one we use. Second, we need to verify that tightening in credit standards explains part of this relation. This analysis is best conducted at the individual investment level and we thus begin by this discussion. 
Working with individual investment returns. Different from Section II where we study portfolio returns, we now cast our analysis at the investment level. Investment characteristics are important control variables when identifying the relation between private equity returns and macroeconomic variables. Forming portfolios would result in a loss of this investment level information. In addition, the advantages of forming portfolios, which we mentioned in Section 3, do not apply to the present analysis.

The investment returns are measured by the annualized MIRR (with S\&P 500 reinvestment rate) described in Section 2. It measures the performance over the life of the investment. We thus simply compute our explanatory variables as average realization between the starting date and the ending date of the investment. For instance, we relate the MIRR of an investment to i) the average realization of market liquidity innovations over the life of that investment (labelled "P\&S liquidity conditions"), ii) the average change in credit standards during the life of that investment (labelled "Tightening of credit standards"), etc.

As we observe outliers on the right tail of returns, we winsorize the MIRR at the 95th percentile. ${ }^{17}$ Also, because the Survey of Loan Officers from the Federal Reserve is continuously available only from April 1990, we focus on the investments that are started after this date. This reduces the sample to 3,763 investments out of the original 4,403 observations. ${ }^{18}$

Shocks to market liquidity and investment returns. Figure 3 provides a graphical impression on the relation between investment returns and liquidity conditions by plotting the average MIRR by deciles of $\mathrm{P} \& \mathrm{~S}$ liquidity conditions. The relation is almost monotonic and the difference in performance between investments going through bad versus good liquidity conditions is a striking $46 \%$ per year.

Of course, this relation does not account for a number of other potentially important determinants of private equity returns. To this purpose, Table VII shows the results from a multiple regression analysis. In all specifications, we include a set of control variables. We have fund size, which is measured as the dollar amount that is committed to the private equity fund that makes the investment (in January 2007 dollars). Fund size is included because, among other things, it may capture the liquidity level of the investment. Larger 
funds, being more visible and experienced, may be able to exit investments more quickly and with less price impact. Controlling for the liquidity level of the investment is important to disentangle the effect of the liquidity level from the effect of liquidity risk on average returns (see the Internet Appendix for a more detailed discussion on this point).

Also, we control for investment level variables such as the stage (a dummy variable that is one if it is a growth investment), the investment size (equity invested, expressed in January 2007 in US dollars), the country of investment location, the industry of the investment, as well as the return on the stock market (CRSP universe).${ }^{19}$ All the explanatory variables are standardized. ${ }^{20}$ In addition, the standard errors are clustered at the investment starting year, because the performance of investments starting at the same time may be driven by unobserved common factors.

In the first specification in Table VII, the effect of liquidity conditions on private equity performance is economically and statistically significant. A one-standard deviation increase in liquidity conditions raises the annual MIRR by $11.4 \%$. This confirms the results in Section II and Figure 3. A deterioration in market liquidity negatively affects private equity returns.

Shocks to funding liquidity and investment returns. The next step involves the test of our conjecture that the effect of market liquidity on private equity returns originates from the relationship between these two variables and funding liquidity. Hence, in the second specification in Table VII, we regress the MIRR on the tightening of credit standards (our chosen measure for deteriorating funding liquidity) and the same set of control variables as above. Consistent with our hypothesis, when credit standards get tightened performance is significantly lower.

In the third specification, we test whether the funding liquidity channel explains the impact of market liquidity on private equity performance. Confirming our conjecture, credit conditions absorb half of the Pástor and Stambaugh liquidity effect. The coefficient on liquidity conditions decreases from $11.4 \%$ to $5.1 \%$ when we add the tightening in credit standards and remains significant at the 5\% confidence level. This robust and significant effect of market liquidity may be interpreted as the manifestation that the tightening in credit standards is an imperfect measure of funding liquidity. It is also possible that channels 
other than refinancing risk explain the relation between market liquidity and private equity performance, which opens an area for future research. ${ }^{21}$

The close connection between credit conditions and liquidity conditions is also apparent from the correlation matrix in Table VIII. The variable most tightly linked to P\&S liquidity conditions is the tightening in credit standards (-63\% correlation), followed by stock-market returns $(46 \%)$. The other variables are only weakly related to credit conditions.

We find these results important for two related reasons. First, they deepen our understanding of the economic channel underlying the relationship between private equity returns and market liquidity. The market liquidity variable is closely related to a measure of funding liquidity, which in turn is a determinant of the ease of refinancing for leveraged deals as shown by Axelson, Jenkinson, Strömberg, and Weisbach (2010).

Second, as a by-product of our analysis, we find some empirical support for the theory of Brunnermeier and Pedersen (2009) relating funding liquidity to market liquidity. Our evidence shows that there is a negative relationship between a dry-up in funding liquidity (the tightening in credit standards) and innovations in market liquidity (the Pástor and Stambaugh measure).

Tables VII and VIII here

\section{B.2. Robustness}

Controlling for the risk of economic conditions. The liquidity effect that we have just shown can be the result of a positive 'macroeconomic' environment which fosters both good private equity performance and good liquidity conditions. With the goal of testing alternative explanations for the effect of liquidity conditions, we add controls for the most obvious macroeconomic variables.

Chen, Roll, and Ross (1986) show that two macro factors are priced in the cross-section of expected returns for public equity: the change in credit spreads and the growth in industrial production. According to these authors, the credit spread proxies for the expected risk premium and industrial production growth proxies for changes in future profitability. We thus include these two variables to specifications three and four in Table VII. Neither variable impacts the significance of $\mathrm{P} \& \mathrm{~S}$ liquidity conditions. An increase in credit spreads 
has a negative, although not significant, impact on private equity returns, confirming that credit conditions matter for private equity returns. However, the change in credit spreads appears to be dominated by the tightening of credit standards as a measure of funding liquidity (see also the last specification in Table VII). This is probably due to the fact that the credit spread is a price-based variable which confounds demand and supply effects, unlike the change in credit standards which is a measure of credit supply. This point is probably best illustrated in the context of the recent financial crisis. In the second semester of 2007 , it seems fair to say that refinancing constraints were probably tight. But the credit spreads hardly changed. In fact, they even decreased $(0.97 \%$ in the first semester of 2007 vs. $0.89 \%$ in the second semester of 2007). Credit spreads spiked in January 2008 and December 2008 but, in the other months of 2008, they were at similar levels as in 2002.

To capture the cyclicality in exit opportunities we include a measure of M\&A waves in column six. The effect of liquidity conditions remains significant with a somewhat lower t-statistic, while the M\&A variable is not significant. Spiegel and Wang (2005) and Bandi, Moise, and Russel (2008) argue that the effects on returns of aggregate liquidity and aggregate volatility are closely (negatively) related. So, in the seventh specification, we control for the change in long-term (four years) realized volatility. This control leaves the significance of the credit standards unaffected and is not significant.

Finally, in the last column of VII, all the control variables are included. Liquidity conditions are now significant only at the $10 \%$ level. This reduced significance is probably the combined effect of controlling for the tightening of credit standards and for M\&A waves. The fact that the latter variable also manages to reduce the significance of P\&S liquidity conditions weakly supports the time-varying liquidity of the M\&A market as another channel for liquidity risk in private equity (also see footnote 21).

Asymmetric measure of liquidity conditions. One potential refinement of our measure of liquidity risk is to allow liquidity conditions to affect private equity performance asymmetrically. The intuition stems from the effect of refinancing constraints. If during the investment's life, liquidity has mild positive and negative shocks, then the refinancing constraint will never be very tight and the investment return should not be much affected. 
Instead, a large negative shock followed by a large positive shock may lead to the same average liquidity (over time) but will have made the refinancing constraint binding at one point, with a potentially significant impact on performance.

The literature on market timing (e.g.,Henriksson and Merton (1981)) captures asymmetric exposures by simply breaking down factor returns into positive and negative realizations. We follow this lead to create both a "negative-liquidity-condition" variable and a "positive-liquidity-condition" variable. The "negative-liquidity-condition" variable results from multiplying each shock by a dummy variable that is zero if a shock is positive and one otherwise. The "positive-liquidity-condition" variable is defined symmetrically. Then, as usual, we take the average realization of these variables over the investment's life.

Table IX shows the results for the negative-liquidity-conditions variable. All the specifications mirror the ones in the previous table but use this asymmetric measure of liquidity conditions. Consistent with the above intuition, the effect of liquidity conditions is larger than in the original specifications, in Table VII. For example, in the first column, a one standard-deviation decrease in the liquidity variable reduces returns by $13.8 \%$ annually. This is a $21 \%$ difference in magnitude relative to the slope of the original liquidity variable. Controlling for the tightening in credit standards again cuts the effect of market liquidity in half. ${ }^{22}$

Other robustness tests. In the Internet Appendix, we replicate our analysis using two other market liquidity measures. The Acharya and Pedersen (2005) measure (see also Acharya, Amihud, and Bharath (2010)) is equal to the cross-sectional average of the monthly illiquidity of individual stocks. ${ }^{23}$ Stock illiquidity is measured with the Amihud (2002) ratio, which is of the average ratio over the month of absolute daily returns over daily trading volume.

The Sadka (2006) (also see Sadka (2010)) liquidity measure is a market-wide aggregation of estimated price impact at the stock level. This price impact is composed of a permanent and a transitory part. These two components are estimated from a micro-structure model and use stock transaction data. The permanent component is the one that according to Sadka is priced in public equity and it is thus the one that we use here. 
Panel A of Table A-VI has the results with the Acharya and Pedersen measure. We find that this measure also leads to statistically significant results. We also note that when using the Acharya and Pedersen measure, the liquidity effect is fully explained by our measure of funding liquidity. The results with the Sadka measure in Panel B of Table A-VI follow a similar pattern as for the other two liquidity measures.

In the Internet Appendix Table A-VII, we show the same specifications as in Table VII for the sub-sample of US investments. Although the sample is reduced by half, the economic and statistical significance is remarkably similar.

Averaging shocks over long periods of time naturally leads to a reduction in the dispersion of liquidity conditions across investments and thus a reduction in statistical power. In the Internet Appendix, we re-run our main regressions over sub-samples of investments based on investment duration. The results suggest that taking the average realization of the explanatory variables reduces the statistical power with respect to longest-duration investments. Still, there seems to be enough power left to identify a significant effect of liquidity risk and tightening in credit standards for all other investments.

Finally, in the Internet Appendix, we extend the set of control variables to additional proxies for the risk of macroeconomic conditions (IPO cycles, VIX, inflation) without impacting the main results and show that the liquidity conditions variable retains significance in the long sample (October 1975 - December 2007) for which the tightening of credit standards is not available.

\section{Time-series evidence}

An alternative approach to the cross-sectional analysis in the previous sub-section is to generate an aggregate time-series of private equity payoffs and correlate it with the measures of market liquidity, funding liquidity, etc.

We first aggregate the cash flows (positive and negative) every month. Because of the growth of the private equity industry, this series is strongly upward trended. We thus detrend it by scaling the investments so that exactly $\$ 100$ million is invested each year. The scaling is done pro-rata, based on investment size, such that the cash flows are comparable 
over time. As shown in Figure 4, the time series of cash flows seems stationary and clearly reveals the private equity cycles (to reduce volatility, in the graph we also show the twelvemonth moving average of the series). We notice the low-yielding years around the 1991 crisis, after which dividends went back up in the mid-1990s. The downturn in the 20002003 period is also visible. The large dividends in 2004-5 triggered large fund-raising and large investments, which lowered the net cash flows in 2006. These investments started to give large payoffs in the first part of 2007. Finally, in late 2007 we see the collapse of private equity payoffs coinciding with the onset of the financial crisis.

Table $\mathrm{X}$ shows the results from regressing the time-series of aggregate private equity cash flows onto on the same macroeconomic variables (including the liquidity measures) that we used in the cross-sectional analysis. The variable "tightening of credit standards" is available starting in April 1990. Hence the sample starts in April 1990. The net cash flows are significantly and positively related to the innovations in the Pástor and Stambaugh measure of market liquidity. Also consistent with the preceding analysis, the tightening in credit standards, which we interpret as a deterioration in funding liquidity, is negatively related to private equity net cash flows. Like in the cross-sectional analysis, the tightening in credit standards is the most significant explanatory variable for private equity performance.

These results show that higher net distributions from private equity houses occur during periods of higher liquidity shocks. They bring further empirical support for our hypothesis and above findings. Finally, this exercise has generated an aggregate measure of private equity payoffs that can be used in other applications.

Figure 4 and

Table X here

\section{Conclusions}

Inspired by the recent literature that identifies a liquidity risk factor in the expected returns of stocks and alternative assets, this paper investigates whether private equity returns load on liquidity risk.

Using a novel and comprehensive dataset containing the cash flows from liquidated private equity investments, we find a positive and significant beta of private equity returns on the Pástor and Stambaugh (2003) traded liquidity factor in a model that also includes the 
excess market return, HML, and SMB. The magnitude of the private equity liquidity beta exceeds the corresponding estimate for $86 \%$ of publicly listed stocks. The unconditional liquidity risk premium is about $3 \%$ annually, the total risk premium is about $18 \%$, and the alpha (gross-of-fees) is not statistically different from zero. In a conditional framework, the premium related to liquidity risk is larger than $5 \%$ for a quarter of the sample periods and can represent at times more than half of the total risk premium (these results are in the Internet Appendix).

We explore a potential reason for the observed link between private equity performance and liquidity risk. Private equity investments are sensitive to the liquidity of credit markets because their debts are occasionally refinanced. According to the theory of Brunnermeier and Pedersen (2009), the funding liquidity of private equity lenders (mainly banks and hedge funds) is related to market liquidity, which is the quantity we measure with the Pástor and Stambaugh (2003) factor. Hence, our main conjecture is that the relation between market liquidity and private equity returns is a reflection of the effect of funding liquidity on private equity performance. We test this hypothesis by using the tightening of credit standards from the Federal Reserve's Senior Loan Officer Survey as a measure of the evolution of funding liquidity. Consistent with our conjecture, this variable is strongly related to private equity returns and it accounts for a significant portion of the liquidity effect on returns. This indicates that funding liquidity is an important source of liquidity risk in private equity. Furthermore, as a by-product of our analysis, we find supporting evidence for the link between market and funding liquidity postulated by Brunnermeier and Pedersen (2009).

The results in this paper are relevant for academics, practitioners, and regulators, as we quantify the systematic risks and the pricing efficiency of an asset class that has gained increasing importance in financial markets. Our evidence suggests that the apparently high performance of private equity investments can be largely explained as compensation for the different risk factors to which returns are exposed, and liquidity risk is one important source of this risk premium.

Our results provide practitioners with a hurdle rate to evaluate private equity. Using such a benchmark, they can assess the NPV of their track record. The cost of capital of 
about $18 \%$ in excess of the risk-free rate that we estimate is in sharp contrast to the widelyused hurdle rate of $8 \%$. In addition, our results may call current compensation practices into question. Fund managers and, oftentimes, the private equity team within the investor's organization, receive performance-based compensation if they achieve returns above $8 \%$ per annum, but this hurdle rate seems low in view of our findings. Knowing the risk profile of private equity investments is also an important input for portfolio risk management. At times of liquidity crises, these investments may not offer the risk-diversification that investors expect from them.

Regulators may also find some useful insights in our results. Solvency II and Basel II require insurance companies and banks to set aside a provision for the risk on their private equity investments (see Bongaerts and Chalier (2009)). As the current method of weighting assets by risk does not reflect the large exposure to liquidity risk, this may result in too low a provision.

Finally, for academics, this paper finds that the liquidity risk factor identified in public equity is consistently related to private equity performance. This contributes to the recent literature showing the pervasiveness of liquidity risk across asset classes. 


\section{References}

Acharya, Viral, Yakov Amihud, and Sreedhar Bharath, 2010, Liquidity risk of corporate bond returns, Working Paper, NYU Stern School of Business.

Acharya, Viral V., and Lasse H. Pedersen, 2005, Asset pricing with liquidity risk, Journal of Financial Economics 77, 375-410.

Acharya, Viral V., Thomas Philippon, Matthew Richardson, and Nouriel Roubini, 2009, A bird's eye view - the financial crisis of 2007-2009: Causes and remedies, in Viral Acharya, and Matthew Richardson, ed.: Restoring Financial Stability: How to Repair a Failed System (Wiley \& Sons: Hoboken,NY).

Amihud, Yakov, 2002, Illiquidity and stock returns: Cross-section and time-series effects, Journal of Financial Markets 5, 31-56.

Amihud, Yakov, Haim Mendelson, and Lasse H. Pedersen, 2005, Liquidity and asset prices, Foundations and Trends in Finance 1(4), 269-364.

Ang, Andrew, Jun Liu, and Krista Schwarz, 2010, Using stocks or portfolios in tests of factor models, Working paper. Columbia University.

Axelson, Ulf, Tim Jenkinson, Per Strömberg, and Michael Weisbach, 2010, Borrow Cheap, Buy High? Determinants of Leverage and Pricing in Buyouts, Working paper. Dice Center Fisher College of Business.

Axelson, Ulf, Per Strömberg, and Michael Weisbach, 2009, Why are buyouts levered? the financial structure of private equity funds., Journal of Finance 64(4), 1549-1582.

Baker, Malcolm, and Jeremy C. Stein, 2004, Market liquidity as a sentiment indicator, Journal of Financial Markets 7, 271-299.

Bandi, Federico M., Claudia E. Moise, and Jeremy R. Russel, 2008, The joint pricing of volatility and liquidity, Working Paper. University of Chicago.

Beber, Alessandro, Michael W. Brandt, and Kenneth A Kavajecz, 2008, Flight to quality or flight to liquidity? Evidence from the Euro-area bond market, Review of Financial Studies 22, 925-957.

Bekaert, Geert, Campbell Harvey, and Christian Lundblad, 2007, Liquidity and expected returns: Lessons from emerging markets, Review of Financial Studies 20, 1783-1831. 
Bernstein, Shai, Josh Lerner, Morten Sorensen, and Per Strömberg, 2010, Private equity and industry performance, NBER Working Paper 15632.

Bongaerts, Dion, and Erwin Chalier, 2009, Private equity and regulatory capital, Journal of Banking and Finance 33, 1211-1220.

Bongaerts, Dion, Frank de Jong, and Joost Driessen, 2010, Derivative pricing with liquidity risk: Theory and evidence from the credit default swap market, Journal of Finance 66(1), 203-240.

Boyson, Nicole M., Chrostof W. Stahel, and René M. Stulz, 2010, Hedge fund contagion and liquidity, Journal of Finance 65(5), 1789-1816.

Brunnermeier, Markus K., and Lasse H. Pedersen, 2009, Market liquidity and funding liquidity, Review of Financial Studies 22, 2201-2238.

Campbell, John Y., and Samuel B. Thompson, 2008, Predicting excess stock returns out of sample: Can anything beat the historical average?, Review of Financial Studies 21, $1509-1531$.

Chan, Louis K. C., Narasimhan Jegadeesh, and Josef Lakonishok, 1995, Evaluating performance of value versus glamour stocks, the impact of selection bias, Journal of Financial Economics 38, 269-296.

Chen, Nai-Fu, Richard Roll, and Stephen A. Ross, 1986, Economic forces and the stock market, Journal of Business 59, 383-403.

Chordia, Tarun, Asani Sarkar, and Avanidhar Subrahmanyam, 2005, An empirical analysis of stock and bond market liquidity, Review of Financial Studies 18, 85-129.

Cochrane, John, 2005, The risk and return of venture capital, Journal of Financial Economics $75,3-52$.

Cumming, Douglas J., Daniel Schmidt, and Uwe Walz, 2010, Legality and venture capital governance around the world, Journal of Business Venturing 25, 54-72.

Cumming, Douglas J., and Uwe Walz, 2010, Private equity returns and disclosure around the world, Journal of International Business Studies 41, 727-754.

D’Agostino, Ralph B., Albert Belanger, and Ralph B. D'Agostino Jr., 1990, A suggestion for using powerful and informative tests of normality, The American Statistician 44(4), 
$316-321$.

Driessen, Joost, Tse-Chun Lin, and Ludovic Phalippou, 2011, A new method to estimate risk and return of non-traded assets from cash flows: The case of private equity funds, Journal of Financial and Quantitative Analysis, forthcoming.

Fama, Eugene, and Kenneth R. French, 1993, Common risk factors in the returns on stocks and bonds, Journal of Financial Economics 33, 3-56.

Ferson, Wayne, and Campbell R. Harvey, 1991, The variation of economic risk premiums, Journal of Political Economy 99, 385-415.

Ferson, Wayne, and Campbell R. Harvey, 1999, Conditioning variables and the cross-section of stock returns, Journal of Finance 54, 1325-1360.

Goyal, Amit, and Ivo Welch, 2008, A comprehensive look at the empirical performance of equity premium prediction, Review of Financial Studies 21(4), 1455-1508.

Henriksson, Roy D., and Robert C. Merton, 1981, On market timing and investment performance. ii. statistical procedures for evaluating forecasting skills, Journal of Business $54(4), 513-533$.

Jagannathan, Ravi, and Zhenyu Wang, 1996, The conditional capm and the cross-section of expected returns, Journal of Finance 51, 3-53.

Kaplan, Steven, and Antoinette Schoar, 2005, Private equity performance: Returns,persistence and capital flows, Journal of Finance 60, 1791-1823.

Kaplan, Steve, and Per Strömberg, 2009, Leveraged buyouts and private equity, Journal of Economic Perspectives 23, 121-146.

Korteweg, Arthur, and Morten Sorensen, 2010, Risk and return characteristics of venture capital-backed entrepreneurial companies, Review of Financial Studies, forthcoming.

Krohmer, Philipp, Rainer Lauterbach, and Victor Calanog, 2009, The bright and dark side of staging: Investment performance and the varying motivations of private equity, Journal of Banking and Finance 33, 1597-1609.

Leary, Mark T., 2008, Bank loan supply, lender choice and corporate capital structure, Journal of Finance 63(4), 2013-2059.

Lerner, Josh, and Antoinette Schoar, 2004, The illiquidity puzzle: Evidence from private 
equity partnerships, Journal of Financial Economics 72, 3-40.

Lewellen, Jonathan, and Stefan Nagel, 2006, The conditional capm does not explain assetpricing anomalies, Journal of Financial Economics 82, 289-314.

Li, Haitao, Junbo Wang, Chunchi Wu, and Yan He, 2009, Are liquidity and information risks priced in the treasury bond market?, Journal of Finance 64, 467-503.

Ljungqvist, Alexander, Matthew Richardson, and Daniel Wolfenzon, 2008, The investment behavior of buyout funds, NBER Working Paper No. 14180.

Longstaff, Francis A., Sanjay Mithal, and Eric Neis, 2005, Corporate yield spreads: Default or Liquidity? New evidence from the credit default swap market, Journal of Finance 60, $2213-2253$.

Longstaff, Francis A., Jun Pan, Lasse H. Pedersen, and Kenneth J. Singleton, 2011, How sovereign is sovereign credit risk?, American Economic Journal: Macroeconomics 3(2), 75-103.

Lopez-de-Silanes, Florencio, Ludovic Phalippou, and Oliver Gottschalg, 2009, Giants at the gate: Private equity investments: Performance and diseconomies of scale, Working Paper. University of Amsterdam.

Lown, Cara, and Donald P. Morgan, 2006, The credit cycle and the business cycle: New findings using the loan officer opinion survey, Journal of Money Credit and Banking 38(6), $1575-1597$.

Metrick, Andrew, and Ayako Yasuda, 2010, The economics of private equity funds, Review of Financial Studies 23, 2303-2341.

Newey, Whitney K., and Kenneth D. West, 1987, A simple, positive semi-definite, heteroskedasticity and autocorrelation consistent covariance matrix, Econometrica 55(3), $703-708$

Pástor, Lubos, and Robert F. Stambaugh, 2003, Liquidity risk and expected stock returns, Journal of Political Economy 111, 642-685.

Phalippou, Ludovic, 2009, Beware of venturing into private equity, Journal of Economic Perspectives 23, 147-66.

Sadka, Ronnie, 2006, Momentum and post-earnings-announcement drift anomalies: The 
role of liquidity risk, Journal of Financial Economics 80, 309-349.

Sadka, Ronnie, 2010, Liquidity risk and the cross-section of expected hedge-fund returns, Journal of Financial Economics 98(1), 54-71.

Spiegel, Matthew I., and Xiaotong Wang, 2005, Cross-sectional variation in stock returns: Liquidity and idiosyncratic risk, Yale ICF Working Paper No. 05-13.

Strömberg, Per, 2007, The new demography of private equity, Working Paper. SIFR.

Vayanos, Dimitri, 2001, Strategic trading in a dynamic noisy market, Journal of Finance $56,131-171$.

Vayanos, Dimitri, 2004, Flight to quality, flight to liquidity, and the pricing of risk, Working Paper. London School of Economics. 
Table I: Cash flows of a typical investment. The table shows the cash flows of a representative investment. It lasts for four years, pays a final dividend equal to 1.5 times the original investment, and pays an intermediate dividend in year 2.5 equals to half of the initial investment. We show the computation of the modified IRR with a re-investment rate of $5 \%$ per semester. At the bottom of the table we report the present value of the dividends using two different discount rates.

\begin{tabular}{rrr}
\hline $\begin{array}{l}\text { Date } \\
\text { (in years) }\end{array}$ & Cash flows & $\begin{array}{r}\text { Re-invested dividend } \\
\text { (at 5\% per semester) }\end{array}$ \\
0 & -100 & 0 \\
0.5 & 0 & 0 \\
1 & 0 & 0 \\
1.5 & 0 & 0 \\
2 & 0 & 0 \\
2.5 & 50 & 50 \\
3 & 0 & 53 \\
3.5 & 0 & 55 \\
4 & 150 & 208 \\
MIRR $=\quad(208 / 100)^{1 / 4}-1=20 \%$ & & 119 \\
IRR = & & 108 \\
Present value of dividends at $15 \%$ discount rate \\
Present value of dividends at 18\% discount rate
\end{tabular}




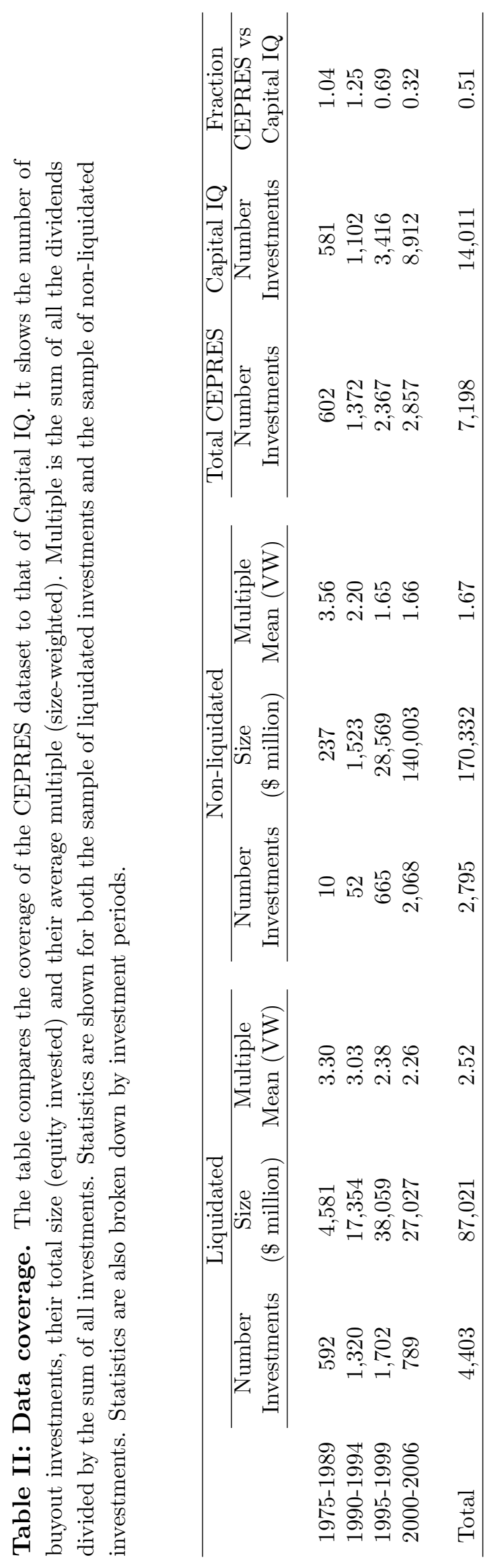


Table III: Data representativeness. This table compares the success rates of PE houses included in the CEPRES dataset and of PE houses that are not included in the CEPRES dataset. The universe of PE houses and their success ratio comes from Thomson Venture Economics. Successful exit rate is the fraction of investments exited via IPO or M\&A over the total number of investments. Only investments made before 2002 and PE houses with more than 5 investments are considered.

\begin{tabular}{lccc}
\hline & CEPRES & TVE (ex-CEPRES) & $\begin{array}{c}\text { Difference } \\
(1)\end{array}$ \\
\cline { 2 - 4 } & 117 & 535 & -418 \\
Number of PE houses & & & \\
Successful-exit rate & 0.43 & 0.39 & 0.04 \\
20th percentile & 0.61 & 0.56 & 0.05 \\
50th percentile & 0.75 & 0.72 & 0.03 \\
80th percentile & 0.59 & 0.55 & 0.04 \\
Mean & & &
\end{tabular}


Table IV: Performance by year and region. The table reports the modified IRR of a group of investments. Groups are based on the year of investment initiation and the region where the investment is located. Performance is computed on the pooled cash flows of each group. The reinvestment rate is the return on the $\mathrm{S} \& \mathrm{P} 500$ index.

Panel A: Modified Internal Rates of Return (S\&P as re-investment rate)

\begin{tabular}{|c|c|c|c|c|c|}
\hline & 1975-1989 & 1990-1994 & 1995-1999 & $2000-2006$ & $1975-2006$ \\
\hline US & 0.18 & 0.18 & 0.19 & 0.13 & 0.18 \\
\hline UK & 0.17 & 0.16 & 0.17 & 0.20 & 0.17 \\
\hline Europe (ex-UK) & 0.17 & 0.14 & 0.25 & 0.21 & 0.20 \\
\hline Rest world & 0.21 & 0.15 & 0.18 & 0.17 & 0.17 \\
\hline All countries & 0.18 & 0.17 & 0.21 & 0.21 & 0.19 \\
\hline \multicolumn{6}{|c|}{ Panel B: Number of Investments } \\
\hline & $1975-1989$ & 1990-1994 & 1995-1999 & $2000-2006$ & $1975-2006$ \\
\hline US & 323 & 533 & 534 & 237 & 1627 \\
\hline UK & 172 & 440 & 526 & 139 & 1277 \\
\hline Europe (ex-UK) & 68 & 269 & 499 & 246 & 1082 \\
\hline Rest world & 17 & 23 & 121 & 152 & 313 \\
\hline All countries & 592 & 1320 & 1702 & 789 & 4403 \\
\hline
\end{tabular}


Table V: Correlations and distributions of the traded factors. This table shows the correlation matrix and summary statistics for the (time-series of the) four traded risk factors: the illiquid-minus-liquid factor by Pastor and Stambaugh (2003), the excess market return, HML, and SMB. The time period is from October 1975 to December 2007. The frequency is monthly. Returns are in percentages.

\begin{tabular}{lrrrr}
\hline & IML_PS & Rm-Rf & HML & SMB \\
\cline { 2 - 5 } Correlations: & & & & \\
IML_PS & 1.000 & & & \\
Rm-Rf & -0.100 & 1.000 & & \\
HML & -0.276 & -0.460 & 1.000 & \\
SMB & 0.042 & 0.236 & -0.341 & 1.000 \\
& & & & \\
Mean & 0.375 & 0.630 & 0.417 & 0.241 \\
St. Deviation & 4.138 & 4.320 & 3.009 & 3.166 \\
5th percentile & -5.767 & -6.410 & -3.960 & -4.180 \\
Median & 0.608 & 0.940 & 0.370 & 0.120 \\
95th percentile & 5.530 & 7.010 & 5.330 & 4.800 \\
\hline
\end{tabular}


Table VI: Risk models and the cost of capital. The table reports the results of OLS estimation of three different factor models for private equity returns (Panel A) and the resulting alphas and cost of capital (Panel B). In Panel A, the dependent variable is the logarithm of one plus the monthly MIRR minus the log of one plus the risk-free rate. Each observation corresponds to a portfolio of private equity investments formed by the starting date of the investment. Portfolios must contain at least twenty investments. Each observation is weighted by the square root of the investment duration to correct for unequal variance. Explanatory variables include the Fama and French (1993) three factors (excess market return, HML, SMB) and the illiquid minus liquid portfolio (IML_PS) by Pastor and Stambaugh (2003). Each explanatory variable is computed by taking its average value during the portfolio life. All variables are in monthly frequency. All specifications are run between October 1975 and December 2007. The table also reports the estimate of the residual standard deviation (sigma) and the number of observations (N). In Panel B, the risk premium is the sum of the products of the factor loadings times the average factor realizations. The cost of capital is the sum of the average risk-free rate plus the risk premium. Alphas and betas are computed using Equations (6) and (7) in the text. The reported values (in \%) are annualized by multiplying the monthly estimate by 12 . In this panel, we also report the annualized average net risk-free rate. The standard errors for Panel B estimates are computed using the delta method. T-statistics are given in parentheses.

\begin{tabular}{lccc}
\multicolumn{4}{l}{ Panel A: Risk Models } \\
\hline Model: & Market & FF & PS \\
\hline \multirow{2}{*}{ IML_PS } & & & 0.638 \\
& & & $(3.539)$ \\
Rm-Rf & 0.948 & 1.395 & 1.294 \\
& $(6.688)$ & $(5.443)$ & $(5.227)$ \\
HML & & 0.719 & 1.020 \\
& & $(2.450)$ & $(3.466)$ \\
SMB & & -0.124 & -0.040 \\
& & $(-0.497)$ & $(-0.167)$ \\
Constant & 0.006 & 0.000 & -0.002 \\
& $(6.003)$ & $(0.035)$ & $(-0.712)$ \\
Sigma & 0.049 & 0.048 & 0.046 \\
Adj. R2 & 0.849 & 0.853 & 0.865 \\
N & 139 & 139 & 139 \\
& & & \\
\hline
\end{tabular}


Table VI: continued.

Panel B: Alpha, Risk Premium, and Cost of Capital

\begin{tabular}{|c|c|c|c|}
\hline Model: & Market & $\mathrm{FF}$ & PS \\
\hline Total Risk premium & $\begin{array}{l}7.300 \% \\
(6.723)\end{array}$ & $\begin{array}{c}14.048 \% \\
(4.485)\end{array}$ & $\begin{array}{c}17.997 \% \\
(5.635)\end{array}$ \\
\hline $\begin{array}{l}\text { Risk premium components: } \\
\beta_{l i q} \times \mu_{l i q}\end{array}$ & & & $\begin{array}{l}2.928 \% \\
(3.599)\end{array}$ \\
\hline$\beta_{m k t} \times \mu_{m k t}$ & $\begin{array}{l}7.300 \% \\
(6.723)\end{array}$ & $\begin{array}{c}10.745 \% \\
(5.505)\end{array}$ & $\begin{array}{l}9.980 \% \\
(5.312)\end{array}$ \\
\hline$\beta_{h m l} \times \mu_{h m l}$ & & $\begin{array}{l}3.668 \% \\
(2.485)\end{array}$ & $\begin{array}{l}5.207 \% \\
(3.527)\end{array}$ \\
\hline$\beta_{s m b} \times \mu_{s m b}$ & & $\begin{array}{c}-0.365 \% \\
(-0.504)\end{array}$ & $\begin{array}{r}-0.118 \% \\
(-0.170)\end{array}$ \\
\hline Risk free rate (in sample) & $5.816 \%$ & $5.816 \%$ & $5.816 \%$ \\
\hline Cost of Capital (in sample) & $\begin{array}{l}13.116 \% \\
(12.080)\end{array}$ & $\begin{array}{c}19.864 \% \\
(6.341)\end{array}$ & $\begin{array}{c}23.813 \% \\
(7.456)\end{array}$ \\
\hline Alpha & $\begin{array}{c}9.303 \% \\
(10.324)\end{array}$ & $\begin{array}{l}3.128 \% \\
(1.227)\end{array}$ & $\begin{array}{l}0.413 \% \\
(0.158)\end{array}$ \\
\hline
\end{tabular}




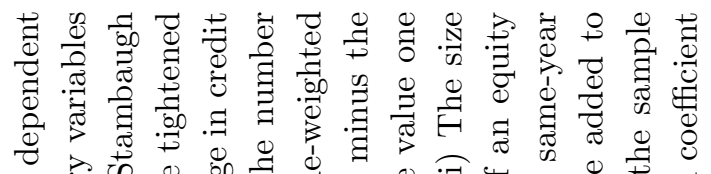

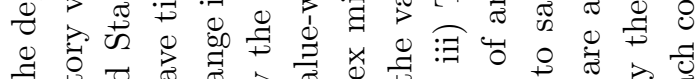

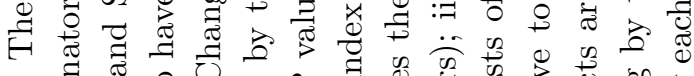

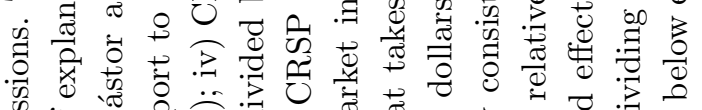

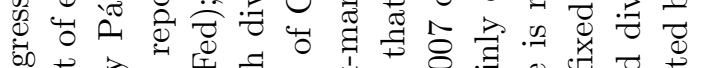

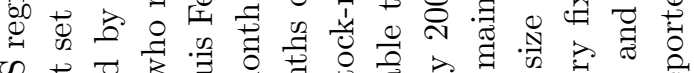

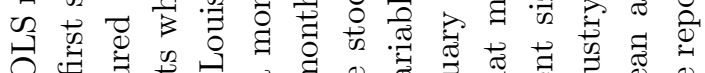

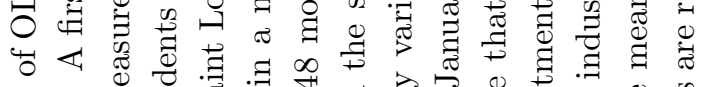

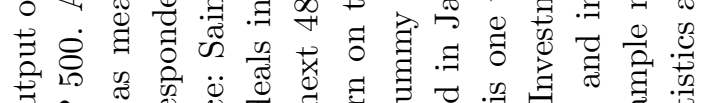

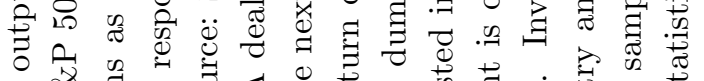

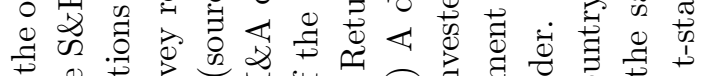

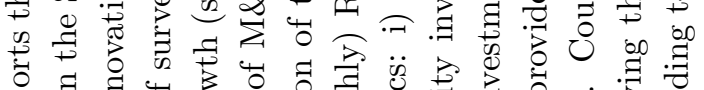

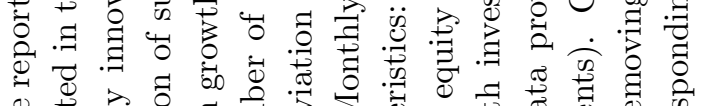

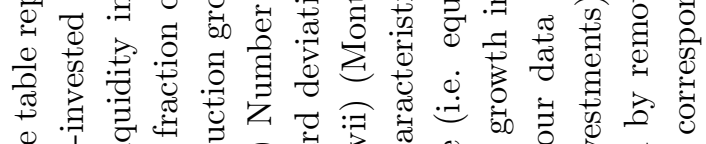

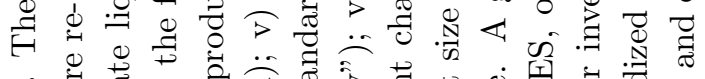

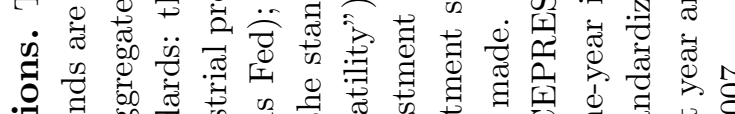

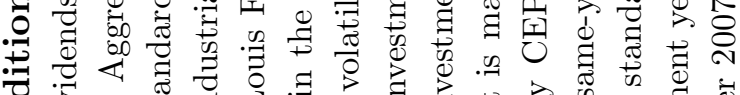

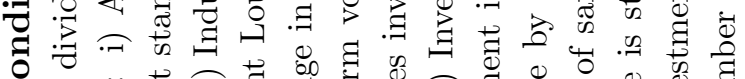

ठ 讨

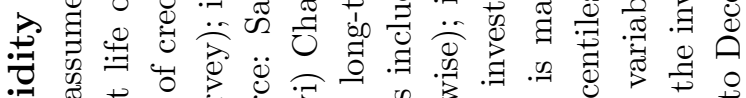

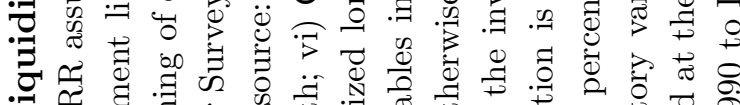

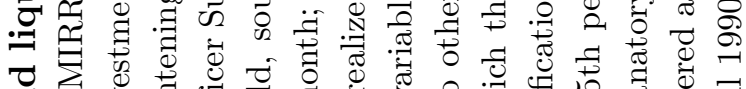

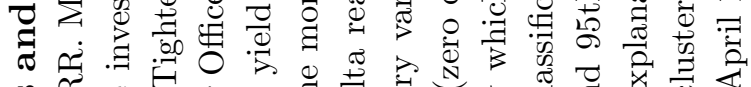

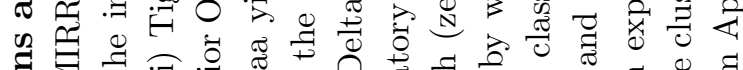

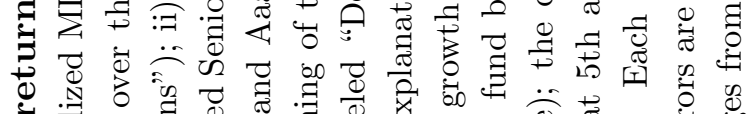

$+\cdots$ of

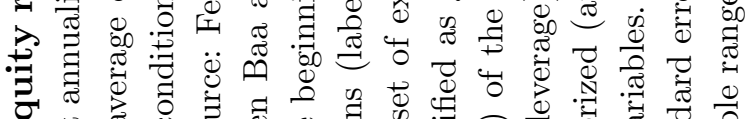

ఫ్

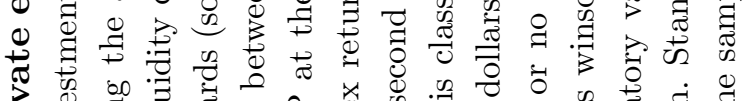

.

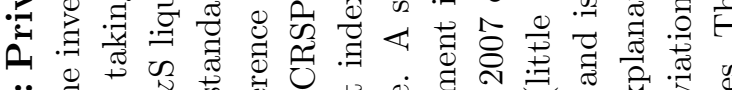

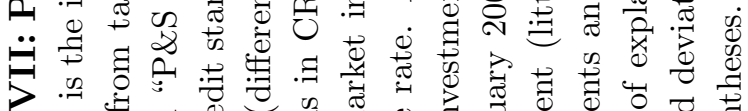

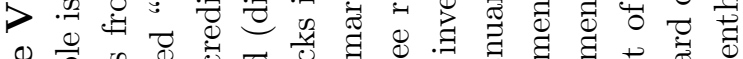

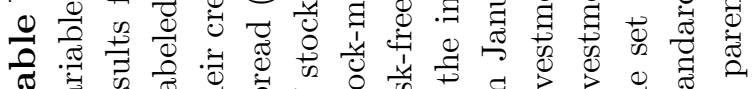

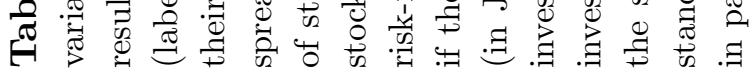




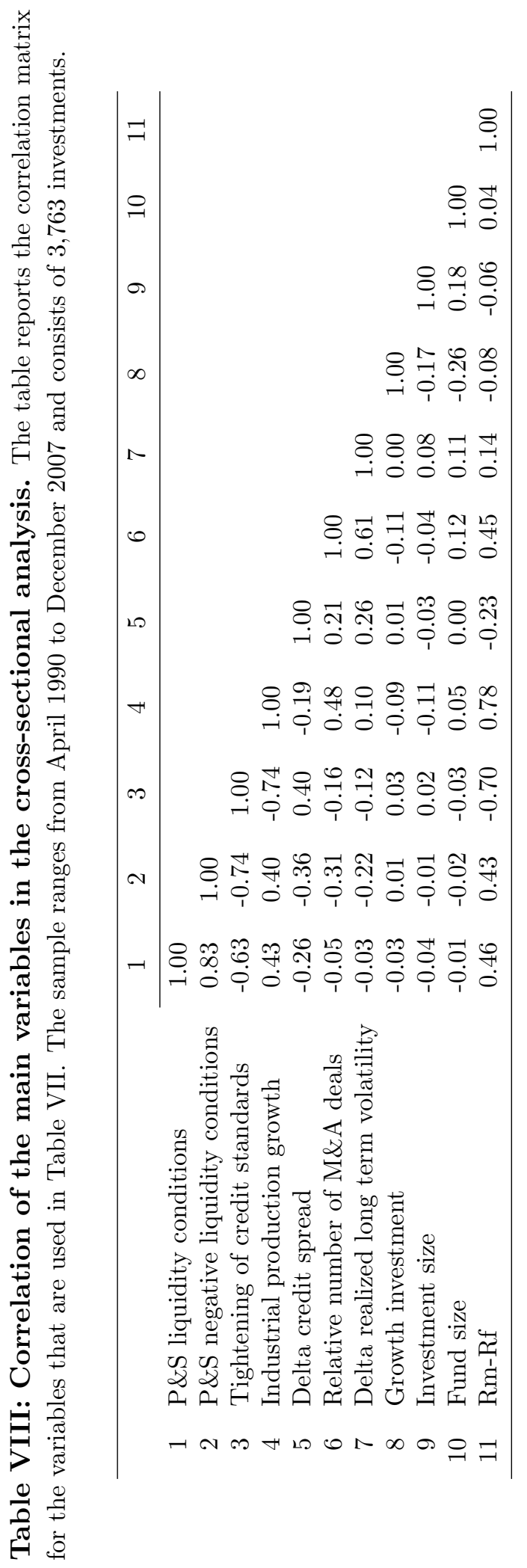


‡

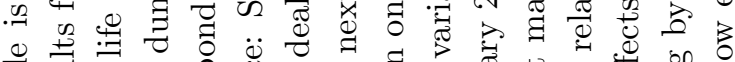

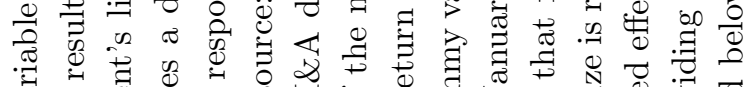

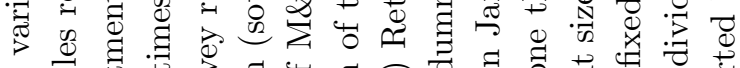

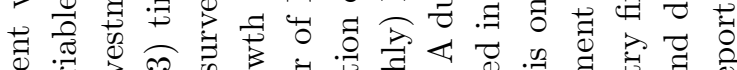

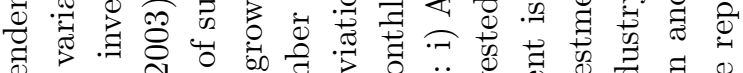

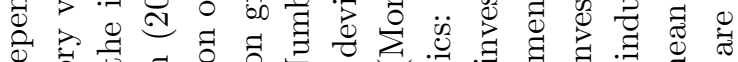

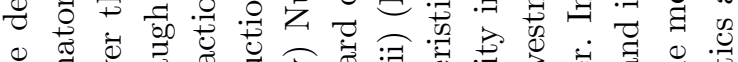

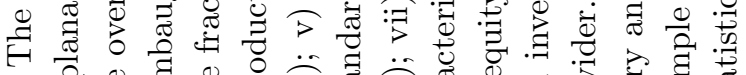

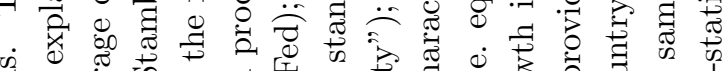

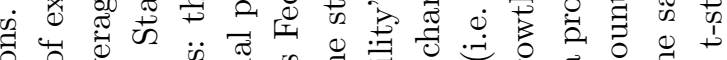

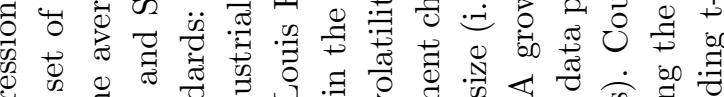

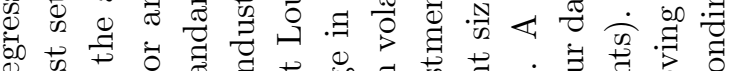

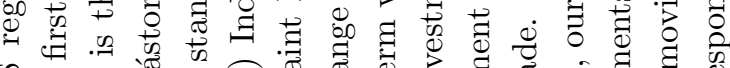

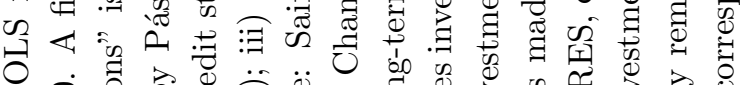

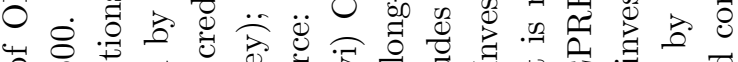

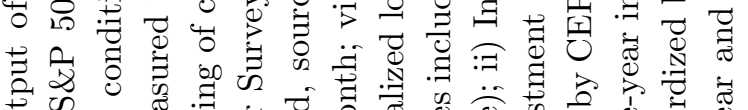

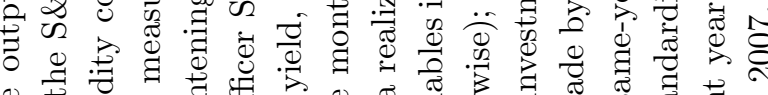

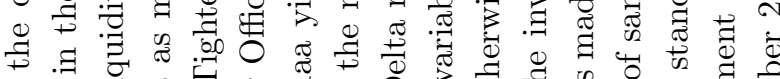
की

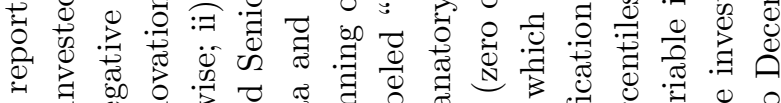
.

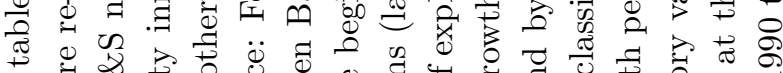
ब

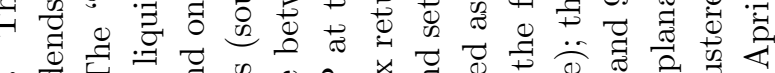

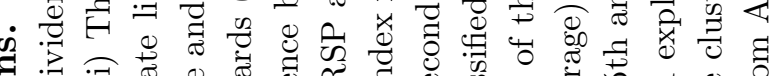

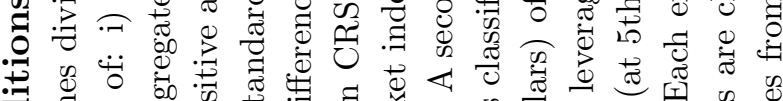

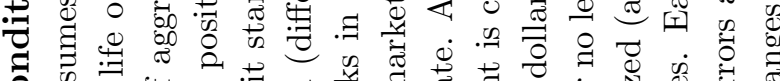
ర) 入

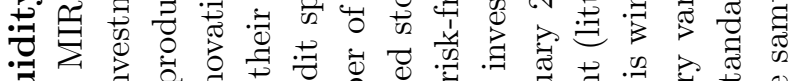

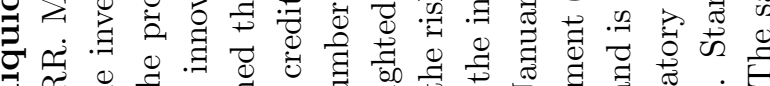

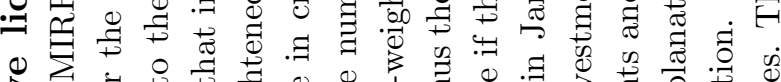

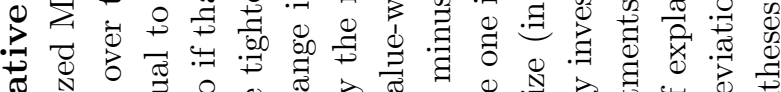

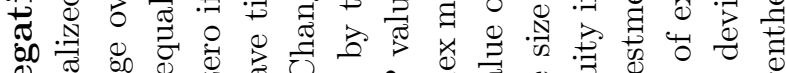

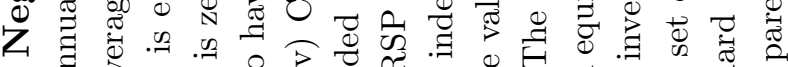

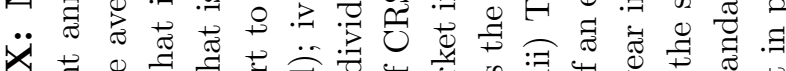
- 苟击

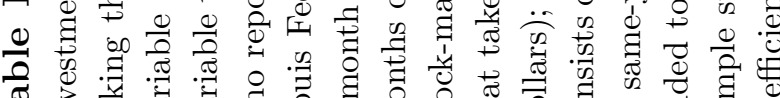

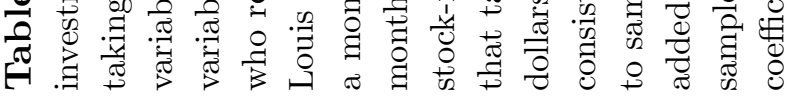

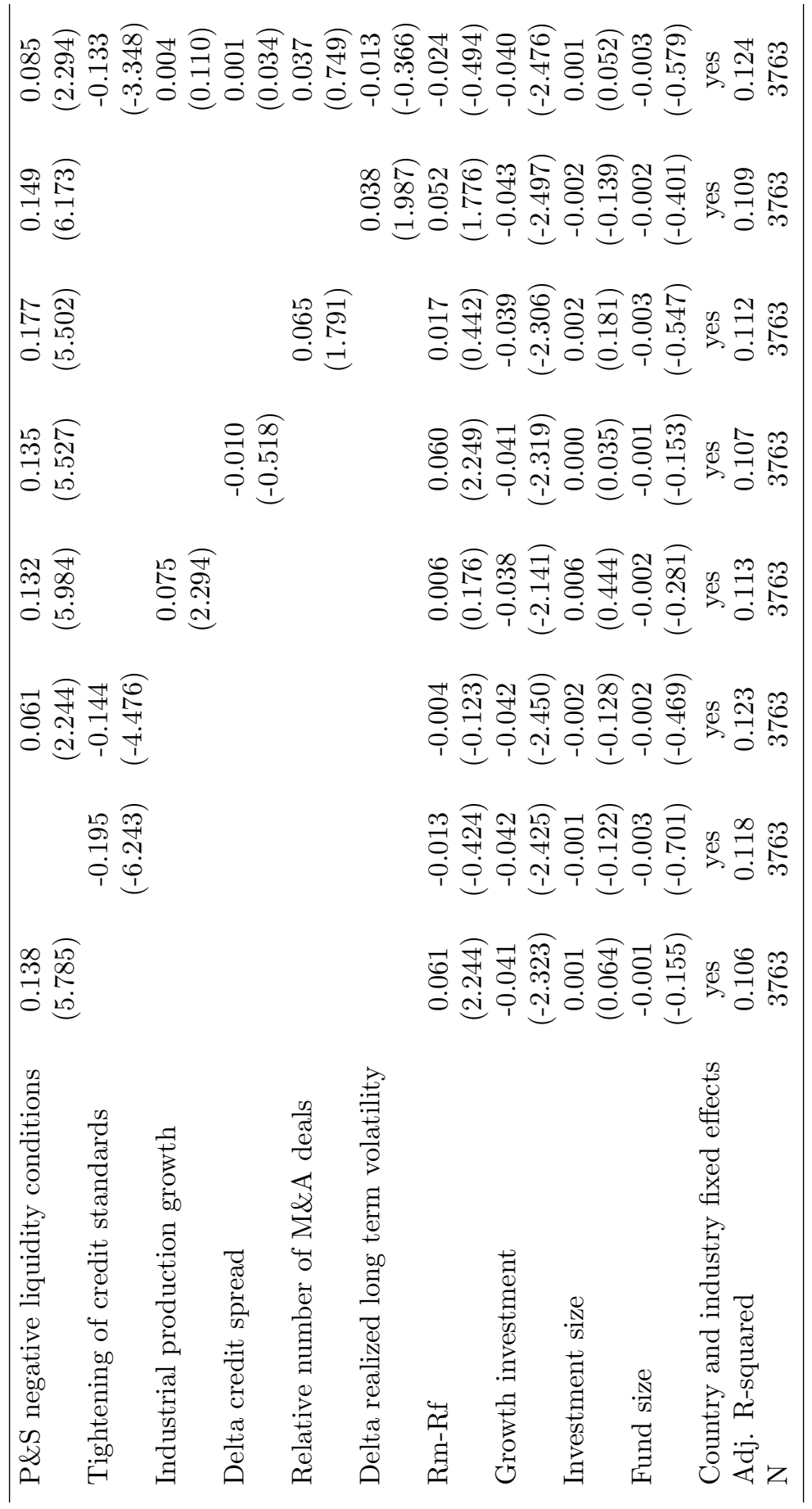




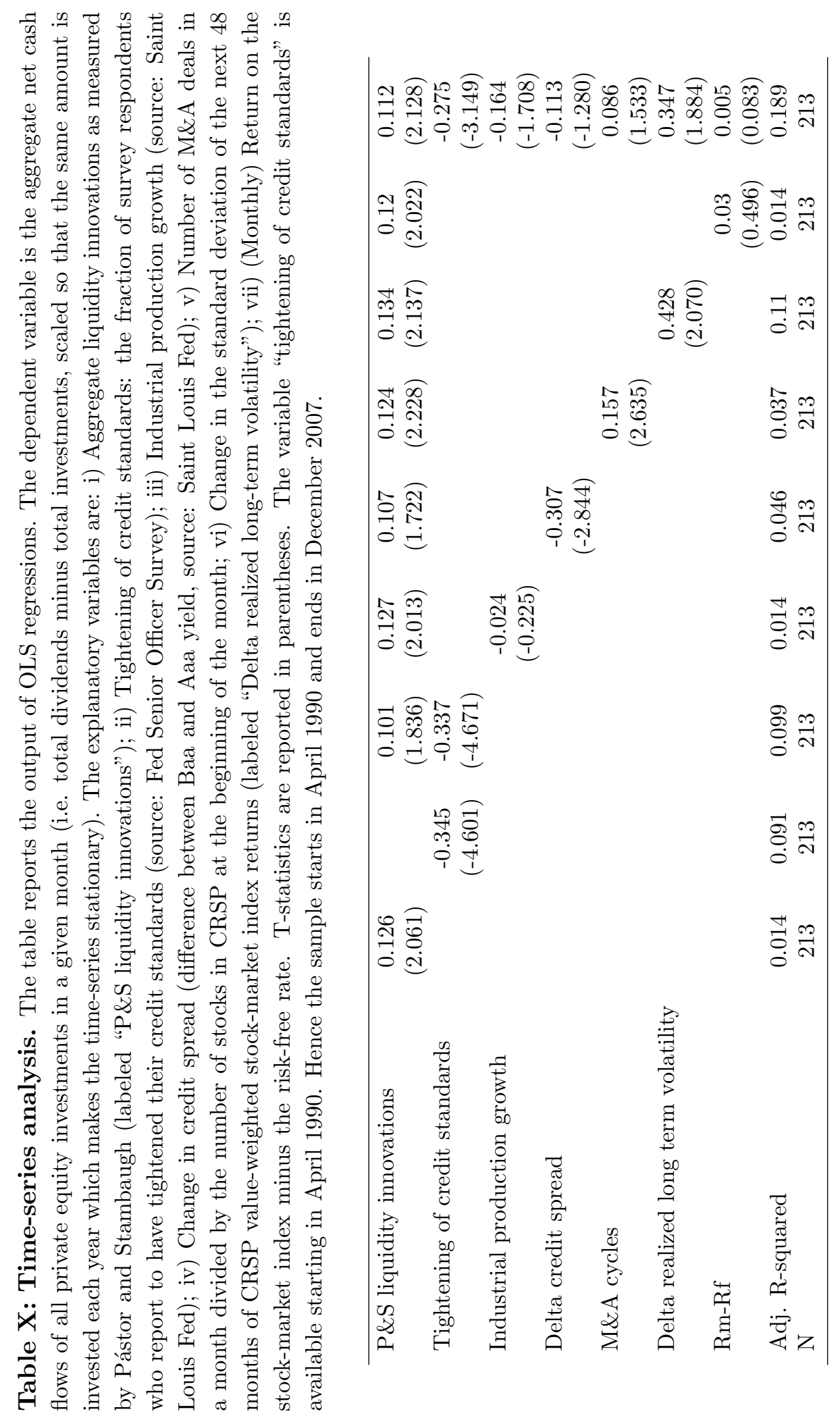


Figure 1: Histogram of MIRR. The figure plots the histogram for the annual MIRR with S\&P 500 as the assumed reinvestment rate. The first bin contains all the investments with MIRR of $-100 \%$ annually. The last bin contains all the investments with MIRR of over $125 \%$ annually.

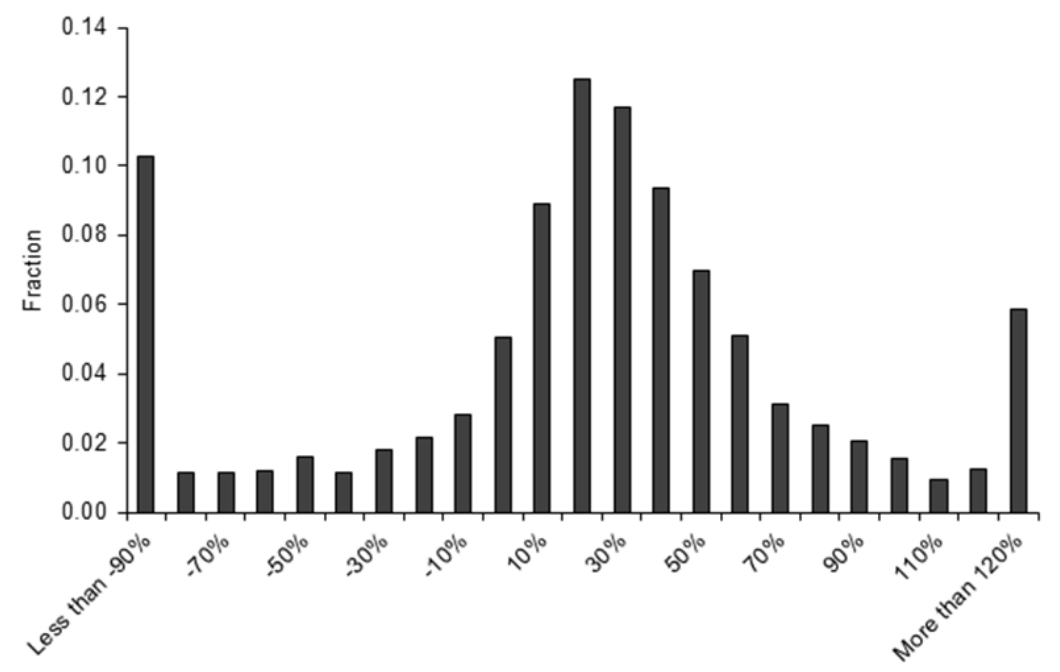


Figure 2: Liquidity Betas for Listed Stocks. The figure plots the histogram for the liquidity betas from the four-factor model devised by Pástor and Stambaugh (2003) for all listed stocks in the CRSP database with at least two years of monthly returns between January 1966 and December 2008 (20,500 stocks).

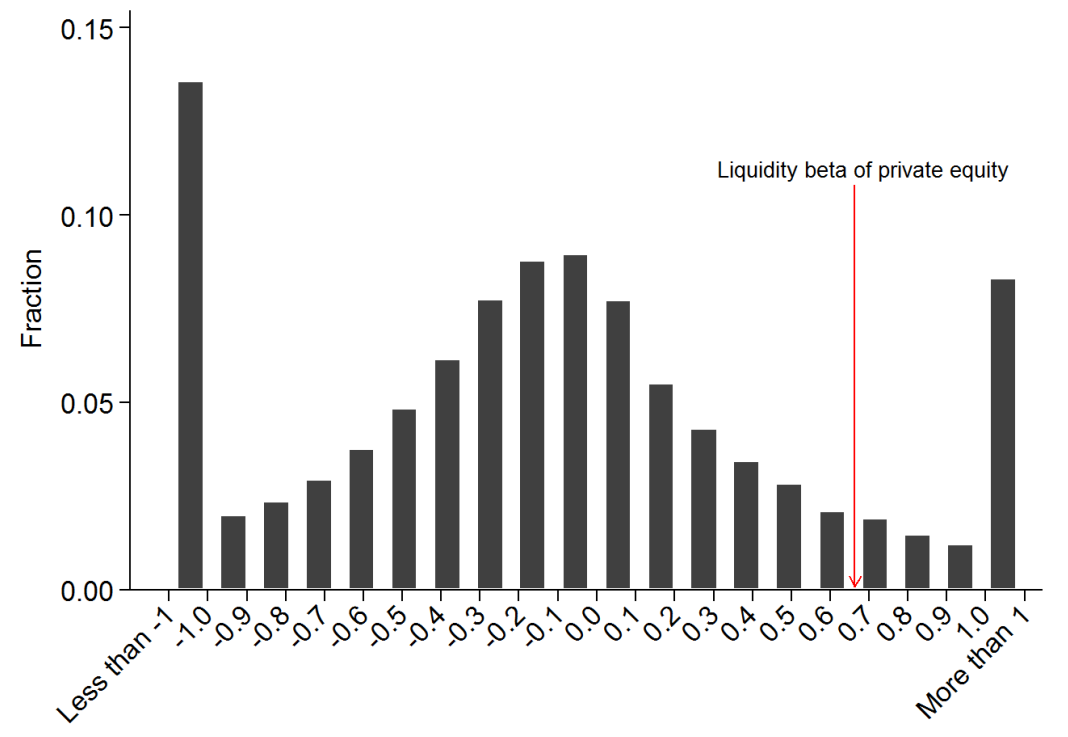

Figure 3: Annual performance by deciles of liquidity conditions. The figure plots the average investment MIRR in each decile of the Pástor and Stambaugh (2003) liquidity condition variable.

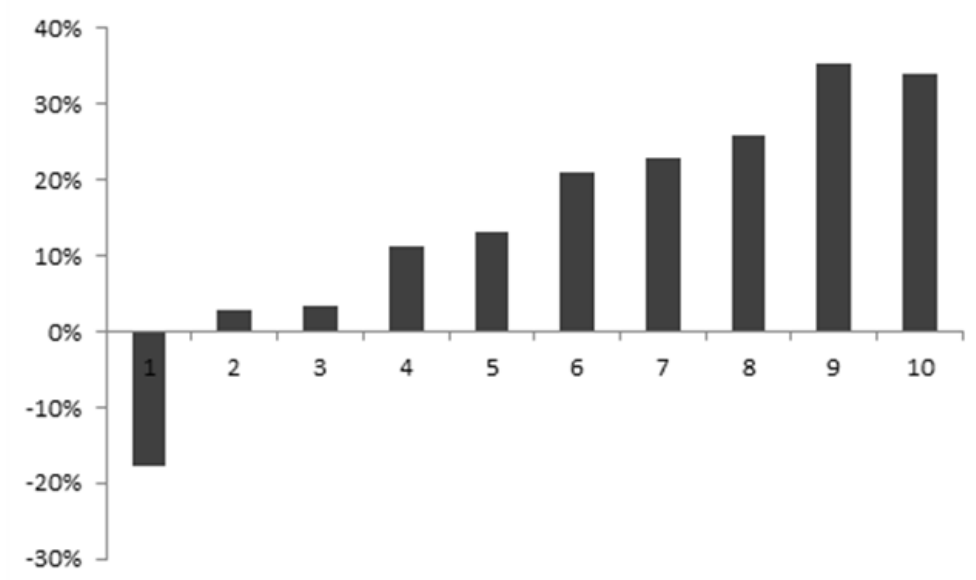


Figure 4: Aggregate net cash flows from private equity investments. The figure shows the aggregate net cash flows from private equity investments from September 1990 to December 2007 (dashed line). Each investment in the sample is scaled so that exactly $\$ 1$ million is invested in each year. The scaling is pro-rata, based on investment size. Cash flows are dividends minus investments each month after the scaling, in millions of U.S. dollars. The graph also shows the 12-month moving average of the time-series of cash flows (solid line).

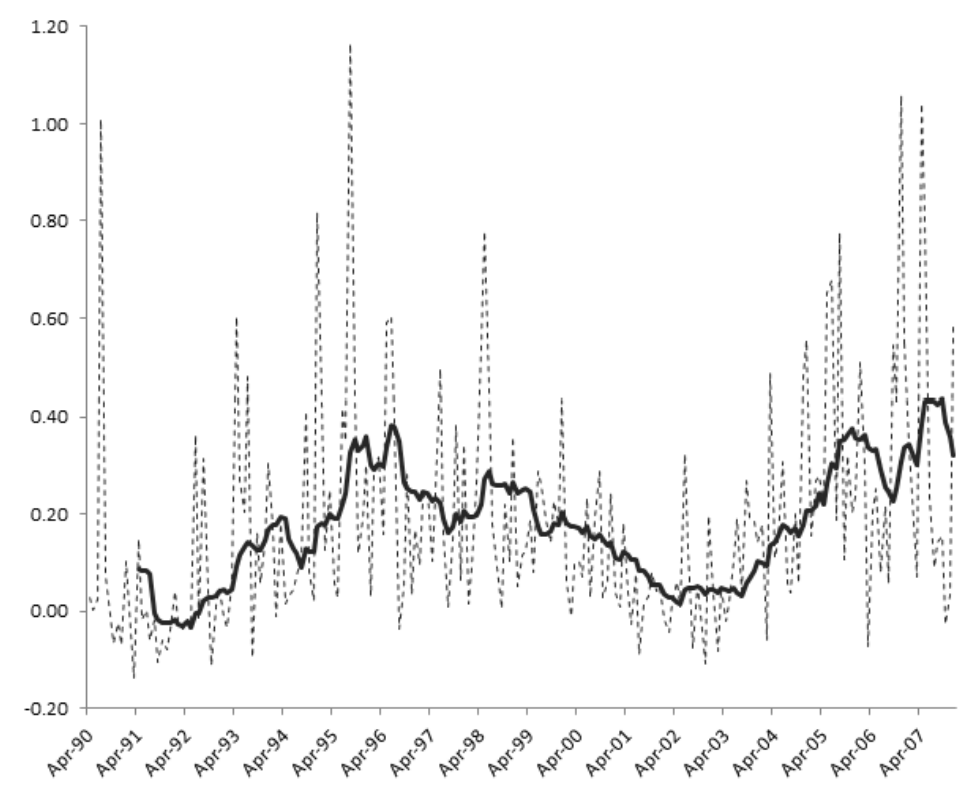




\section{Notes}

${ }^{1}$ Note that the focus of this paper is on systematic risk originating from time-varying liquidity, rather than on the asset-specific liquidity characteristic, the liquidity level. See the Internet Appendix for a more detailed discussion of this distinction. A new strand of literature in asset pricing has established liquidity risk as a priced factor in public equity returns (e.g., Pástor and Stambaugh (2003), Acharya and Pedersen (2005), Sadka (2006)). This evidence has been later extended to emerging markets (Bekaert, Harvey, and Lundblad (2007)), bond markets (Beber, Brandt, and Kavajecz (2008), Chordia, Sarkar, and Subrahmanyam (2005), Li, Wang, Wu, and He (2009), and Acharya, Amihud, and Bharath (2010)), credit derivative markets (Longstaff, Mithal, and Neis (2005), Bongaerts, de Jong, and Driessen (2010), and Longstaff, Pan, Pedersen, and Singleton (2011)), and hedge funds (Sadka (2010) and Boyson, Stahel, and Stulz (2010)).

${ }^{2}$ In addition, adapting Ferson and Harvey's (1999) conditional approach, we find that the expected liquidity risk premium varies over time and it is higher than $5 \%$ annually in one month out of four. The conditional analysis is reported in the Internet Appendix of the paper.

${ }^{3}$ Leary (2008) also uses this measure to proxy for loan supply.

4 "Private equity houses" refers to organizations that run private equity funds which in turn make private equity investments in portfolio companies.

${ }^{5}$ Two proprietary databases similar to the CEPRES dataset are used in contemporary research. Ljungqvist, Richardson, and Wolfenzon (2008) have data from a large investor. Our data spans a similar time period to theirs, but contains about twice as many investments. Lopez-de-Silanes, Phalippou, and Gottschalg (2009) have a dataset containing the performance of private equity investments from hand-collected private placement memoranda, but do not have the detailed cash flows generated for each investment.

${ }^{6}$ In order to compute a meaningful success ratio, we restrict investments to those made before 2002. It would not be fair to classify as unsuccessful investments made less than 5 
years ago and not exited yet. We also require at least five investments per firm. CEPRES performed the calculations for us in order to preserve anonymity. They counted 117 firms in their dataset that satisfy these criteria. In Thomson Venture Economics, they counted 535 firms that satisfy these criteria but were not included in their database.

${ }^{7}$ This is an approximation. Carried interest equals $20 \%$ of the returns. The $2 \%$ management fee is charged on a mix of capital invested and committed, and is typically equivalent to a $3 \%$ fee on capital invested (see Metrick and Yasuda (2010) and Phalippou (2009) for details).

${ }^{8}$ Cochrane (2005) and Korteweg and Sorensen (2010) highlight the role played by sample selection bias when estimating risk models for venture capital investments. In their context, valuations are observed only infrequently, although more often for well-performing investments. Explicit modeling of the selection mechanism is thus required to obtain unbiased estimates of factor loadings and alphas. Because our data do not suffer from such a severe sample selection bias, we can simplify their approach and simply estimate the factor models with OLS regressions.

${ }^{9}$ Given the monthly frequency of the factors, we set the interval length to one month. This choice has no material consequences, except for interpretation of the reported coefficients. Notice also that, unlike Cochrane (2005), we choose to express normally distributed factors in levels rather than logs. The reason is that factors are based on long-short strategies and can take negative values, which does not allow logarithmic transformation. This fact causes minor deviations from Cochrane in the formulas for factor loadings and alphas that we derive in the Internet Appendix.

${ }^{10} \mathrm{GLS}$ is the most efficient estimation method with non-spherical disturbances.

${ }^{11}$ In a recent paper, Ang, Liu, and Schwarz (2010) compare the cost and benefits of portfolio formation when conducting a two-step Fama-McBeth procedure. Forming portfolios improves the estimation of beta but reduces the precision for the estimation of the risk premium. Since we only estimate betas, Ang, Liu, and Schwarz (2010) provide further support 
for the use of portfolios as opposed to individual investments.

${ }^{12}$ In the Internet Appendix tables, we show robustness to different choices for the minimum number of investments per portfolio.

${ }^{13}$ Notice that adding the estimates of alpha and the cost of capital in Panel B of Table VI gives an estimate for the expected return on private equity of about $24 \%$. This estimate is larger than the 19\% average return that we report in Panel A of Table IV. The spread is due to the fact that Table IV has the average geometric return $\left(R_{g}^{i}\right)$, whereas the $24 \%$ estimate refers to arithmetic returns $\left(R_{t+1}^{i}\right)$. Whenever the volatility of returns is not zero, the geometric return is smaller than the arithmetic return.

${ }^{14}$ As mentioned above, our choice of a minimum number of twenty investments per portfolio may be considered arbitrary. To address this concern, Tables A-III and A-IV in the Internet Appendix report the results with alternative choices for this minimum threshold. The threshold cannot drop below five investments otherwise we have a portfolio with a $-100 \%$ return. With a threshold of fifty investments per portfolio, the number of portfolios drops to sixty-eight, so we do not raise the threshold further. In general, results seem stable throughout the spectrum of chosen thresholds.

${ }^{15}$ Note that the $7.5 \%$ liquidity risk premium reported by Pastor and Stambaugh (2003) is the beta of a long-short position on the top and bottom decile stocks by liquidity betas and it is not the liquidity risk premium paid by the average stock. In fact, by construction the aggregate public equity portfolio will have a zero beta on the liquidity factor, SMB and HML, and a beta of one on the market factor in a four-factor model. Hence any asset class with a liquidity beta higher than zero will bear greater liquidity risk than the public equity portfolio. Furthermore, notice that in our sample (October 1987 - December 2007) the Pastor-Stambaugh factor pays a $4.5 \%$ premium, which is less than the $7.5 \%$ in the $1963-$ 1999 sample used in the original Pastor and Stambaugh (2003) paper. This observation gives more economic significance to the $2.9 \%$ liquidity premium that we obtain for private equity. 
${ }^{16}$ In a statement that provides support for this refinancing risk channel for private equity, Acharya, Philippon, Richardson, and Roubini (2009, p.9) argue that as a consequence of the recent liquidity crisis " [...] a large number of leveraged loans that are coming to maturity in 2010 and 2011 [...] may go bust once the refinancing crisis emerges". Also, a recent study by Standard \& Poors (2009) corroborates this prediction and shows that, following the last financial crisis, defaults increased substantially due to covenant breaches, especially among large portfolio companies (so-called mega-buyouts).

${ }^{17}$ The 95 th percentile is $135 \%$ annually and the 99 th percentile is $400 \%$ annually. Winsorizing at the 99th percentile leads to slightly stronger results.

${ }^{18}$ In the Internet Appendix, we have results for the full sample of 4,403 that do not use the credit standards variable. The positive relation between P\&S liquidity conditions and private equity returns holds significantly also in the full sample.

${ }^{19}$ We control for the country and industry of the investment with fixed effects. A growth investment is an investment which is meant to finance the growth of a company. It usually involves less leverage than leveraged buyouts and usually is a minority stake (unlike leveraged buyouts). As investment size increases over time, we subtract the annual mean from each observation. In addition, as there are some outliers in terms of investment size, we winsorize this variable at the 95 th percentile.

${ }^{20}$ The coefficients can then be interpreted as the impact of a one-standard-deviation change in the explanatory variable on annual returns. Importantly, inference is not affected by the transformation. The t-statistics are exactly the same with and without the standardization.

${ }^{21}$ Acharya and Pedersen (2005) argue that liquidity risk originates from uncertainty about the transaction costs faced when selling an asset. A simple example delineates how this story can be relevant in a private equity context. Let us consider the uncertainty about transaction costs that an investor faces when selling two different equity positions: A and B. A is a $\$ 10$ million position in a $\mathrm{S} \& \mathrm{P} 500$ company. B is a $\$ 10$ million investment representing 
a $100 \%$ stake in a privately-held business. When selling A, an investor has some flexibility to manage transaction costs: for example, he can limit its price impact by splitting the order (Chan, Jegadeesh, and Lakonishok (1995), Vayanos (2001)). This possibility is not available for asset B. In addition, market depth is probably better for A. The number of potential investors in A certainly varies over time, but there are always enough investors willing to purchase a $\$ 10$ million stake in a $\mathrm{S} \& \mathrm{P} 500$ company at a reasonable price. In contrast, the market for full ownership of a privately-held business is significantly smaller. To exit a privately held investment, the two main routes are a trade sale or an IPO. Both of these exit channels have proven to be cyclical in the past. When exiting during a trough in the IPO or M\&A cycle, transaction costs are probably substantial, but they will be minimal in a buoyant IPO or M\&A market. We partly test this story in the robustness analysis by adding the M\&A cycles variables. In combination with credit tightening and the other controls, this regressor reduces the significance of $\mathrm{P} \& \mathrm{~S}$ liquidity conditions (see the last specification in Table VII).

${ }^{22}$ The results for the positive-liquidity-condition variable are given in a Internet Appendix. We find that, consistent with the refinancing constraints argument, positive liquidity innovations are not significantly related to returns.

${ }^{23}$ Their original variable is one of market illiquidity and so we change its sign for consistency with the other measures. 


\section{Internet Appendix for: Private Equity Performance and Liquidity Risk}

\section{Derivation of the expressions for alpha and beta}

In this appendix, we provide the explicit derivation of equations (6) and (7) in the text. The reported formulas differ slightly from the formulas in Cochrane (2005), because we have a multifactor model and the factors are not in logarithmic form.

From equation (2), $R_{t+1}^{i}$ is the exponential of a normally distributed variable:

$$
R_{t+1}^{i}=R_{t+1}^{f} e^{\gamma+\delta^{\prime} f_{t+1}+\varepsilon_{t+1}^{i}}
$$

Also, by assumption, the factors are normal. Hence, the expression of the expected return is

$$
E\left(R_{t+1}^{i}\right)=R_{t+1}^{f} e^{\gamma+\delta^{\prime} \mu_{F}+\frac{1}{2} \delta^{\prime} \sigma_{F}^{2} \delta+\frac{1}{2} \sigma^{2}}
$$

Applying Stein's lemma, the covariance can be expressed as

$$
\begin{aligned}
\operatorname{Cov}\left(f_{t+1}, R_{t+1}^{i}\right) & =\operatorname{Cov}\left(f_{t+1}, \delta^{\prime} f_{t+1}+\varepsilon_{t+1}^{i}\right) E\left(R_{t+1}^{i}\right) \\
& =\operatorname{Cov}\left(f_{t+1}, \delta^{\prime} f_{t+1}+\varepsilon_{t+1}^{i}\right) R_{t+1}^{f} e^{\gamma+\delta^{\prime} \mu_{F}+\frac{1}{2} \delta^{\prime} \sigma_{F}^{2} \delta+\frac{1}{2} \sigma^{2}} \\
& =\operatorname{Var}\left(f_{t+1}\right) \delta R_{t+1}^{f} e^{\gamma+\delta^{\prime} \mu_{F}+\frac{1}{2} \delta^{\prime} \sigma_{F}^{2} \delta+\frac{1}{2} \sigma^{2}}
\end{aligned}
$$

where, for the last step, we use the fact that $\varepsilon_{t+1}^{i}$ and $f_{t+1}$ are uncorrelated. The expression for beta then follows:

${ }^{*}$ Citation format: Francesco Franzoni, Eric Nowak, and Ludovic Phalippou, [year], Internet Appendix to "Private Equity Performance and Liquidity Risk," Journal of Finance [vol ], [pages], http://www.afajof.org/IA/[year].asp. Please note: Wiley-Blackwell is not responsible for the content or functionality of any supporting information supplied by the authors. Any queries (other than missing material) should be directed to the authors of the article. 


$$
\begin{aligned}
\beta & =\operatorname{Var}\left(f_{t+1}\right)^{-1} \operatorname{Cov}\left(f_{t+1}, R_{t+1}^{i}\right) \\
& =\operatorname{Var}\left(f_{t+1}\right)^{-1} \operatorname{Var}\left(f_{t+1}\right) \delta R_{t+1}^{f} e^{\gamma+\delta^{\prime} \mu_{F}+\frac{1}{2} \delta^{\prime} \sigma_{F}^{2} \delta+\frac{1}{2} \sigma^{2}} \\
& =\delta R_{t+1}^{f} e^{\gamma+\delta^{\prime} \mu_{F}+\frac{1}{2} \delta^{\prime} \sigma_{F}^{2} \delta+\frac{1}{2} \sigma^{2}}
\end{aligned}
$$

To compute alpha we use the standard definition

$$
\alpha=E\left(R_{t+1}^{i}\right)-R_{t+1}^{f}-\beta^{\prime} E\left(f_{t+1}\right)
$$

where $E\left(f_{t+1}\right)=\mu_{f}$. Replacing the expressions for the expected return in (A1) and beta in $(\mathrm{A} 3)$, we get

$$
\alpha=R_{f}\left(e^{\gamma+\delta^{\prime} \mu_{F}+\frac{1}{2} \delta^{\prime} \sigma_{F}^{2} \delta+\frac{1}{2} \sigma^{2}}\left(1-\delta^{\prime} \mu_{F}\right)-1\right)
$$

Although we do not use them in the estimation, it is interesting to derive the continuous time limits for $\alpha$ and $\beta$. These are:

$$
\begin{aligned}
\beta & =\delta \\
\alpha & =\gamma+\frac{1}{2} \delta^{\prime} \sigma_{f}^{2} \delta+\frac{1}{2} \sigma^{2} .
\end{aligned}
$$

To obtain these formulas, one can start from the continuous time equivalent of equation (2)

$$
d \log \left(V_{t}\right)=\gamma d t+r_{f} d t+\delta^{\prime} d f_{t}+\sigma d Z_{t}
$$

where $d f_{t}=\mu_{f} d t+\sigma_{f} d Z_{f, t}, Z_{t}$ and $Z_{f, t}$ are independent vectors of standard Brownian motions, and $r_{f}$ is the instantaneous risk-free rate. Then, apply Ito's lemma to equation (A8) to obtain the process for the return in levels

$$
\frac{d V_{t}}{V_{t}}=\left(\gamma+r_{f}+\delta^{\prime} \mu_{f}+\frac{1}{2}\left(\sigma^{2}+\delta^{\prime} \sigma_{f}^{2} \delta\right)\right) d t+\sigma d Z_{t}+\delta^{\prime} \sigma_{f} d Z_{f}
$$


Then, from equation (A9), we obtain beta using the standard definition

$$
\begin{aligned}
\beta & =\operatorname{Var}\left(d f_{t}\right)^{-1} \operatorname{Cov}\left(d f_{t}, \frac{d V_{t}}{V_{t}}\right) \\
& =\left(\sigma_{f}^{2}\right)^{-1} \sigma_{f}^{2} \delta \\
& =\delta .
\end{aligned}
$$

Finally, to obtain equation (A7), use the definition of alpha and the result in (A10)

$$
\begin{aligned}
\alpha d t & =E\left(\frac{d V_{t}}{V_{t}}\right)-r_{f} d t-\beta^{\prime} E\left(d f_{t}\right) \\
& =\left(\gamma+\frac{1}{2}\left(\sigma^{2}+\delta^{\prime} \sigma_{f}^{2} \delta\right)\right) d t
\end{aligned}
$$




\section{Conditional analysis}

An issue which is always present when estimating risk exposures is that factor loadings may be correlated with factor realizations. A significant covariance between factor loadings and risk premia would cause the unconditional estimates to be biased (e.g., Jagannathan and Wang (1996) and Lewellen and Nagel (2006)). In our context, we can foresee that when expecting poor funding conditions, investment managers may choose to (or be forced to) reduce their exposure to refinancing risk by reducing the leverage ratio for example. This behavior may ultimately induce positive correlation between liquidity risk realizations and loadings, which biases the estimates of alphas and betas, if left unmodeled. To verify whether this is a valid concern, we follow Ferson and Harvey (1991) and Ferson and Harvey (1999) and let the betas be a linear function of conditioning information. In addition, this conditional analysis allows us to document the extent to which the liquidity risk premium varies over time.

\section{A. Empirical framework}

Estimating the conditional risk premium for an asset involves a separate estimation of: i) the conditional beta and ii) the conditional factor risk premium. Then, the conditional risk premium of the asset is the product of the conditional beta and the conditional factor risk premium.

To estimate conditional betas, we adjust the approach of Ferson and Harvey (1999) to our context. We modify equation (4) and let the loading for factor $k$ at time $t$ be a linear function of a set of instruments $Z_{t}$

$$
\delta_{k, t}=b_{k, 0}+b_{k, 1}^{\prime} Z_{t}
$$

Similarly, also the $\gamma$ in equation (4) is allowed to vary over time with the same set of instruments $Z_{t}$

$$
\gamma_{t}=a_{0}+a_{1}^{\prime} Z_{t} .
$$


We obtain estimates of $b_{k, 0}, b_{k, 1}$ from estimating this modified version of equation (4) on the same portfolio data from the previous sub-section and using the same four risk factors. Then, the time-varying risk loadings result from interacting the estimates of $b_{k, 0}, b_{k, 1}$ with the instruments $Z_{t}{ }^{1}$

To estimate the conditional factor risk premia, we run predictive rolling-window regressions. The rolling-window framework is adopted to allow for instability in the coefficients of the predictive regression. The dependent variable is the average realization of the factor in the forty-eight months between $t$ and $t+47,{ }^{2}$ the independent variables are the instruments $Z_{t-1}$ (measured at time $t-1$ ). The estimation sample ranges from month $t-60$ to month $t-1$. Then, the predicted risk premium at time $t$ is constructed by multiplying the slopes from this predictive regression by the instruments measured at time $t$. The estimation sample ranges between October 1975 and December 2007. As suggested by Campbell and Thompson (2008), the predicted factor risk premium is constrained to be positive.

\section{B. Empirical results with the five instruments of Ferson and Harvey (1999)}

First, we use the same five instruments as Ferson and Harvey (1999). These are: (1) the holding period return between time $t-1$ and time $t$ for a three-month T-bill in excess of the return on a one-month T-bill (Bb3, data from CRSP); (2) the dividend yield on the S\&P 500 (DY, data from Prof. Shiller's website); (3) the spread between Moody's Baa and Aaa corporate bond yields (Credit Spread, data from the St. Louis Fed); (4) the spread between a long term (5-year) Treasury bond and one-year Treasury bond yields (Term Spread, data from CRSP); (5) the yield on a one-month T-bill at time $t$ (Y1M).

In Table A-I - Panel A, we report the slopes on the instruments from the conditional estimation of the four betas. Panel $\mathrm{B}$ has the results from the predictive regressions of the four factor risk premia. To avoid reporting 200 regression results here, we report the estimates for December 1975, December 1980, ..., and December 2004 (the last month for which the regression is possible). The standard errors are computed as in Newey and West (1987) with forty-seven lags to account for the autocorrelation of residuals due the overlap in the dependent variable. We note that the instruments display some predictive power for 
the factors. However, the magnitude and sign of the slopes change over time, which justifies our choice of using rolling windows for the estimation sample.

Panel $\mathrm{C}$ reports the distribution of the monthly conditional liquidity risk premium for private equity. We focus first on the results obtained with the conditional forecasts of the factor risk premium. We notice that while the average conditional risk premium is about $2.7 \%$ per year ${ }^{3}$, it ranges between $0 \%$ (at the 25 th percentile) and $5.4 \%$ (at the 75 th percentile). So, in a quarter of the sample months the liquidity risk premium exceeds $5.4 \%$. We also report statistics on the fraction of the total conditional risk premium of private equity (computed as the sum of the risk premia from the four factors) that is accounted for by liquidity risk. This ratio can be computed only in the months when both the numerator and denominator are positive. The ratio is $37.8 \%$ on average and it ranges between $11.8 \%$ (at the 25 th percentile) and $56.7 \%$ (at the 75 th percentile). This shows that quite often liquidity risk can account for more than half of the cost of capital.

Because there is no consensus in the literature on the predictability of factor risk premia (see, e.g., Goyal and Welch (2008)), we also report in Panel C - Table A-I, the results when the forecasted risk premium is simply equal to the unconditional mean of the fortyeight month factor realizations. The variation in the conditional liquidity risk premium is naturally smaller than what we reported above. Yet, liquidity risk continues to represent at times an important component of the total risk premium for private equity.

\section{Empirical results with a restricted set of instruments}

In Table A-I, we note that no instrument is individually significant. We impute the lack of significance to the low power of these tests given that the estimation sample consists of only 139 portfolios. For this reason, we also show results with a narrower set of conditioning variables. The instruments with the best predictive power for the conditionals betas are the Credit Spread and Y1M. Table A-II thus shows the results when we use only these two instruments. As expected, in Panel A, the statistical significance of the instruments is somewhat higher than in the previous table. In particular, we notice that the relation between liquidity risk beta and the Credit Spread is marginally significant at the $10 \%$ level. 
As in the previous table, Panel B shows the predictive regressions for the factor risk premia and we do observe that the instruments are stronger predictors of the factors.

Finally, in Panel C - Table A-II, we notice that the variation in the conditional liquidity risk premium is of similar magnitude to what reported in Table A-I; whether we use conditional forecasts of the factor risk premia or not.

To summarize, we show that in some periods of our sample the conditional liquidity premium goes well beyond the $3 \%$ unconditional estimate. The dependence of the betas on conditioning information appears to be marginal. Rather, much of the time-variation comes from time-variation in the factor risk premia. The finding that the betas are insignificantly related to the conditioning variables that drive the risk premia likely suggests that the covariance between factor loadings and factor risk premia is negligible. This fact, in turn, implies that the asset pricing model holds conditionally as well as unconditionally (see, e.g., Jagannathan and Wang (1996) and Lewellen and Nagel (2006)). This conclusion addresses the concern that motivated us to pursue the conditional analysis and legitimates the results from the unconditional estimation above.

Tables A-I and A-II here

\section{Liquidity risk and liquidity level}

As pointed out by Acharya and Pedersen (2005) among others, liquidity varies over time and it displays commonality across securities and asset classes. Recent theoretical and empirical results in asset pricing suggest that the commonality in liquidity is a priced risk factor (liquidity risk, see footnote 1 for references). The premium in returns that is due to liquidity risk is different from the premium that depends on the average level of liquidity of an asset.

Aggregate liquidity is a priced risk factor in a CAPM world with time varying transaction costs, as in Acharya and Pedersen (2005). In this context, liquidity risk emerges as the covariance of asset specific returns and transaction costs with aggregate transaction costs, which in turn are a component of gross market returns. Also, as argued by Bekaert, Harvey, and Lundblad (2007), aggregate liquidity can become a priced risk factor in rational models where liquidity shocks are correlated with preferences (e.g., Vayanos (2004)) or behavioral 
models where liquidity partially reflects the presence or absence of rational investors in the market (e.g., Baker and Stein (2004)).

Unlike the premium for liquidity risk, the compensation for the average level of liquidity of an asset can emerge even with risk neutral investors. Amihud, Mendelson, and Pedersen (2005) provide a simple explanation. An investor who buys a security and expects to pay transactions costs when selling it, will take this into account and so will do the other investors to which the security is sold. Hence, the price of a security is discounted by the present value of the transaction costs through its life time. This price discount translates into a return premium, which is higher for more illiquid assets.

In this paper we focus on the compensation for systematic risk originating from the covariance of private equity returns with aggregate liquidity (the liquidity risk) rather than on the asset-specific liquidity characteristic (the liquidity level).

As for the premium in private equity returns that originates from the average liquidity level of these investments, the only study touching upon this topic that we are aware of is by Lerner and Schoar (2004). They propose a model and provide supporting empirical evidence showing that the liquidity level of private equity funds is a decision variable for fund managers. Fund managers deliberately make the fund stakes illiquid to screen investors that are less likely to face a liquidity shock.

In our empirical analysis, we control for the liquidity level of the investments using fund size as a proxy (see Table X). Fund size is measured as the dollar amount that is committed to the private equity fund that makes the investment (in January 2007 dollars). We conjecture that this variable proxies for the liquidity level of the investment. The intuition is that bigger funds are raised by more established and visible private equity houses. Hence, they can get better terms when exiting their investments, both in terms of timing and price. In other words, if KKR wants to dispose of an investment it is reasonable to conclude that it can do it more quickly and with less price impact. In all specifications, fund size is not significantly related to returns, while the main results on the impact of liquidity risk on private equity returns are unaffected. Given this evidence, we conclude that observed link between private equity returns and liquidity innovations originates from 
liquidity risk in private equity and is not likely to be due to a premium for the average illiquidity of the investment. 
Table A-I: Conditional analysis: 5 instruments. The table reports results from the estimation of the conditional risk premium of private equity. The conditional liquidity risk premium is the product of the conditional liquidity beta and the conditional risk premium on the Pastor and Stambaugh factor (IML_PS). We proceed in the same way to estimate conditional risk premia originating from the other risk factors (Rm-Rf, HML, SMB). The conditional beta is estimated as in Ferson and Harvey (1999) assuming that beta is a linear function of a set of instruments. For this table, the instruments are: (1) the holding period return between time $t-1$ and time $t$ for a three-month T-bill in excess of the return on a one-month T-bill (Bb3, data from CRSP); (2) the dividend yield on the S\&P 500 (DY, data from Prof. Shiller's website); (3) the spread between Moody's Baa and Aaa corporate bond yields (Credit Spread, data from the St. Louis Fed); (4) the spread between a long term (5-year) Treasury bond and one-year Treasury bond yields (Term Spread, data from CRSP); (5) the yield on a one-month T-bill at time $t$ (Y1M). To estimate the conditional factor risk premia, we run predictive regressions on sixty-month rolling-windows. The dependent variable is the average realization of the factor in the forty-eight months between $t$ and $t+47$, the independent variables are the instruments $Z_{t-1}$ (measured at time $t-1$ ). The estimation sample ranges from month $t-1$ to month $t-60$. Then, the predicted factor risk premium at time $t$ is constructed multiplying the slopes from this predictive regression with the instruments measured at time $t$. As in Campbell and Thompson (2008), whenever the predicted factor risk premium is negative, we replace it with zero. We also report results in which the forecast risk premium is equal to the unconditional mean of the forty-eight month factor realizations. Panel A has the estimates from the conditional beta specifications for each of the four factors. The estimation sample consists of the 139 portfolios of at least twenty private equity investments sorted on their start date. T-statistics are given in parentheses. Panel B has the predictive regression estimates for selected estimation windows. Standard errors are computed as in Newey and West (1987) with forty-seven lags. Tstatistics are given in parentheses. The estimation sample for these regressions ranges between October 1975 and December 2004. Panel C reports the distribution for the conditional liquidity risk premium.

Panel A: Conditional beta regressions

\begin{tabular}{lcccc}
\hline Interaction with: & \multicolumn{4}{c}{ Factors } \\
\cline { 2 - 5 } Bb3 & IML_PS & Rm - Rf & HML & SMB \\
\cline { 2 - 5 } & 2.063 & -0.870 & -7.146 & 9.051 \\
DY & $(0.487)$ & $(-0.130)$ & $(-0.875)$ & $(1.507)$ \\
& -8.969 & -13.082 & -34.656 & -56.101 \\
Credit Spread & $(-0.211)$ & $(-0.171)$ & $(-0.424)$ & $(-0.864)$ \\
& -1.022 & 0.502 & 0.115 & 0.895 \\
Term Spread & $(-0.850)$ & $(0.411)$ & $(0.056)$ & $(0.535)$ \\
& 0.111 & 0.634 & 1.005 & 0.495 \\
Y1M & $(0.222)$ & $(0.786)$ & $(0.892)$ & $(0.631)$ \\
& 1.599 & -0.673 & 1.825 & 2.885 \\
Constant & $(0.616)$ & $(-0.179)$ & $(0.320)$ & $(0.739)$ \\
& 0.821 & 0.200 & -0.462 & -2.402 \\
& $(0.705)$ & $(0.118)$ & $(-0.184)$ & $(-1.307)$ \\
\hline
\end{tabular}




\section{Table A-I: continued.}

Panel B: Predictive regressions for selected months

\begin{tabular}{|c|c|c|c|c|c|c|c|}
\hline \multirow[t]{2}{*}{ Date: } & \multirow[t]{2}{*}{ Forecast factor: } & \multicolumn{6}{|c|}{ Instruments } \\
\hline & & Bb3 & DY & Credit Spread & Term Spread & Y1M & Constant \\
\hline \multirow{8}{*}{ December 1975} & \multirow[t]{2}{*}{ IML_PS } & -0.354 & 0.161 & -2.639 & -0.041 & -46.521 & 3.383 \\
\hline & & $(-1.783)$ & $(0.552)$ & $(-1.879)$ & $(-0.124)$ & $(-3.304)$ & $(6.530)$ \\
\hline & \multirow[t]{2}{*}{$\mathrm{Rm}-\mathrm{Rf}$} & -0.057 & -0.039 & 0.428 & -0.025 & 56.476 & -2.1 \\
\hline & & $(-0.491)$ & $(-0.526)$ & $(0.826)$ & $(-0.134)$ & $(10.245)$ & $(-9.053)$ \\
\hline & \multirow[t]{2}{*}{ HML } & 0.096 & -0.31 & -1.343 & -0.172 & -18.156 & 2.234 \\
\hline & & $(1.024)$ & $(-6.746)$ & $(-4.633)$ & $(-3.538)$ & $(-5.089)$ & $(13.146)$ \\
\hline & \multirow[t]{2}{*}{ SMB } & 0.396 & -0.077 & 2.71 & 0.093 & 40.581 & -2.789 \\
\hline & & $(2.694)$ & $(-0.386)$ & $(2.917)$ & $(0.375)$ & $(3.855)$ & $(-8.329)$ \\
\hline \multirow[t]{8}{*}{ December 1985} & \multirow[t]{2}{*}{ IML_PS } & 0.118 & 0.333 & 0.467 & -0.571 & 16.755 & -0.161 \\
\hline & & (1.077) & $(5.166)$ & $(1.092)$ & $(-4.813)$ & $(2.746)$ & $(-0.228)$ \\
\hline & \multirow[t]{2}{*}{$\mathrm{Rm}-\mathrm{Rf}$} & -0.139 & 0.172 & -0.456 & -0.484 & 48.505 & -0.97 \\
\hline & & $(-2.280)$ & $(8.725)$ & $(-3.823)$ & $(-6.740)$ & $(7.322)$ & $(-3.904)$ \\
\hline & \multirow[t]{2}{*}{ HML } & 0.32 & -0.198 & 0.222 & 0.295 & -18.821 & 0.961 \\
\hline & & $(6.212)$ & $(-4.775)$ & $(1.087)$ & $(3.951)$ & $(-3.111)$ & $(3.609)$ \\
\hline & \multirow[t]{2}{*}{ SMB } & 0.158 & -0.184 & 0.078 & 0.295 & 11.723 & -0.882 \\
\hline & & $(4.244)$ & $(-9.345)$ & $(0.590)$ & $(6.324)$ & $(6.299)$ & $(-6.053)$ \\
\hline \multirow[t]{8}{*}{ December 1995} & \multirow[t]{2}{*}{ IML_PS } & -0.510 & 0.139 & 1.462 & 1.052 & -69.053 & 1.866 \\
\hline & & $(-1.503)$ & $(3.231)$ & $(5.022)$ & $(3.626)$ & $(-3.070)$ & $(5.112)$ \\
\hline & \multirow[t]{2}{*}{$\mathrm{Rm}-\mathrm{Rf}$} & -1.387 & -0.255 & -0.523 & 0.751 & 15.717 & 2.263 \\
\hline & & $(-3.067)$ & $(-9.179)$ & $(-2.606)$ & $(2.285)$ & $(0.483)$ & $(4.214)$ \\
\hline & \multirow[t]{2}{*}{ HML } & 0.357 & 0.153 & 0.582 & -0.652 & 45.189 & -1.714 \\
\hline & & $(4.320)$ & $(4.502)$ & $(2.922)$ & $(-2.654)$ & $(8.304)$ & $(-16.284)$ \\
\hline & \multirow[t]{2}{*}{ SMB } & 1.07 & 0.182 & -0.270 & -0.013 & 12.618 & -1.542 \\
\hline & & $(1.734)$ & $(4.874)$ & $(-0.747)$ & $(-0.051)$ & $(0.323)$ & $(-2.142)$ \\
\hline \multirow[t]{8}{*}{ December 2004} & \multirow[t]{2}{*}{ IML_PS } & -0.152 & 0.192 & -1.681 & 3.115 & 4.816 & 0.324 \\
\hline & & $(-0.515)$ & $(1.369)$ & $(-1.467)$ & $(4.388)$ & $(0.169)$ & $(0.594)$ \\
\hline & \multirow[t]{2}{*}{$\mathrm{Rm}-\mathrm{Rf}$} & 0.917 & 0.208 & 0.836 & 1.74 & 137.81 & -3.019 \\
\hline & & $(3.625)$ & (2.066) & $(1.282)$ & (1.781) & $(6.202)$ & $(-7.293)$ \\
\hline & \multirow[t]{2}{*}{ HML } & 0.162 & -0.023 & 1.877 & -0.244 & 3.600 & 0.137 \\
\hline & & $(0.678)$ & $(-0.255)$ & (2.866) & $(-0.432)$ & $(0.255)$ & $(0.321)$ \\
\hline & \multirow[t]{2}{*}{ SMB } & 0.708 & 0.188 & 3.282 & 2.352 & 27.225 & -1.619 \\
\hline & & $(7.426)$ & $(4.053)$ & $(4.628)$ & $(6.246)$ & $(0.852)$ & $(-2.140)$ \\
\hline
\end{tabular}




\section{Table A-I: continued.}

Panel C: Distribution of the conditional liquidity premium

\begin{tabular}{lcccc} 
& & & \multicolumn{2}{c}{ Interquantile Range } \\
\cline { 4 - 5 } & Mean & Std. Dev. & $25 \%$ & $75 \%$ \\
\hline With conditional forecast of factor risk premia: & & & & \\
Conditional Liquidity Risk Premium (\%, annual) & 2.703 & 4.519 & 0.000 & 5.417 \\
Liquidity Risk Premium / Total Risk Premium (\%) & 37.828 & 27.297 & 11.893 & 56.716 \\
& & & & \\
& & & & \\
With unconditional forecast of factor risk premia: & & & \\
Conditional Liquidity Risk Premium (\%, annual) & 1.894 & 1.764 & 0.969 & 3.126 \\
Liquidity Risk Premium / Total Risk Premium (\%) & 40.780 & 26.855 & 19.105 & 60.055 \\
\hline
\end{tabular}


Table A-II: Conditional analysis: 2 instruments. The table reports results from the estimation of the conditional risk premium of private equity. The conditional liquidity risk premium is the product of the conditional liquidity beta and the conditional risk premium on the Pastor and Stambaugh factor (IML_PS). We proceed in the same way to estimate conditional risk premia originating from the other risk factors (Rm-Rf, HML, SMB). The conditional beta is estimated as in Ferson and Harvey (1999) assuming that beta is a linear function of a set of instruments. For this table, the instruments are: (1) the spread between Moody's Baa and Aaa corporate bond yields (Credit Spread, data from the St. Louis Fed); (2) the yield on a one-month T-bill at time $t(\mathrm{Y} 1 \mathrm{M})$. To estimate the conditional factor risk premia, we run predictive regressions on sixty-month rollingwindows. The dependent variable is the average realization of the factor in the forty-eight months between $t$ and $t+47$, the independent variables are the instruments $Z_{t-1}$ (measured at time $t-1$ ). The estimation sample ranges from month $t-1$ to month $t-60$. Then, the predicted factor risk premium at time $t$ is constructed multiplying the slopes from this predictive regression with the instruments measured at time $t$. As in Campbell and Thompson (2008), whenever the predicted factor risk premium is negative, we replace it with zero. We also report results in which the forecast risk premium is equal to the unconditional mean of the forty-eight month factor realizations. Panel A has the estimates from the conditional beta specifications for each of the four factors. The estimation sample consists of the 139 portfolios of at least twenty private equity investments sorted on their start date. T-statistics are given in parentheses. Panel B has the predictive regression estimates for selected estimation windows. Standard errors are computed as in Newey and West (1987) with forty-seven lags. T-statistics are given in parentheses. The estimation sample for these regressions ranges between October 1975 and December 2004. Panel C reports the distribution for the conditional liquidity risk premium.

Panel A: Conditional beta regressions

\begin{tabular}{lcccc}
\hline Interaction with: & \multicolumn{4}{c}{ Factors } \\
\cline { 2 - 5 } Credit Spread & IML_PS & Rm - Rf & HML & SMB \\
\cline { 2 - 5 } & -1.295 & 0.899 & -1.140 & 1.438 \\
Y1M & $(-1.839)$ & $(0.868)$ & $(-0.700)$ & $(1.167)$ \\
& 0.005 & -3.595 & -5.117 & 0.621 \\
Constant & $(0.004)$ & $(-2.007)$ & $(-2.770)$ & $(0.379)$ \\
& 1.892 & 0.803 & 3.531 & -2.126 \\
& $(2.337)$ & $(0.639)$ & $(2.234)$ & $(-1.629)$ \\
\hline
\end{tabular}


Table A-II: continued.

Panel B: Predictive regressions for selected months

\begin{tabular}{|c|c|c|c|c|}
\hline \multirow[t]{2}{*}{ Date: } & \multirow[t]{2}{*}{ Forecast factor: } & \multicolumn{3}{|c|}{ Instruments } \\
\hline & & Credit Spread & Y1M & Constant \\
\hline \multirow[t]{4}{*}{ December 1975} & IML_PS & $\begin{array}{c}-0.850 \\
(-3.905)\end{array}$ & $\begin{array}{c}-4.779 \\
(-8.733)\end{array}$ & $\begin{array}{c}3.373 \\
(9.783)\end{array}$ \\
\hline & $\mathrm{Rm}-\mathrm{Rf}$ & $\begin{array}{c}0.663 \\
(7.712)\end{array}$ & $\begin{array}{c}2.333 \\
(8.391)\end{array}$ & $\begin{array}{c}-1.831 \\
(-13.263)\end{array}$ \\
\hline & HML & $\begin{array}{c}-0.408 \\
(-3.931)\end{array}$ & $\begin{array}{c}-0.499 \\
(-2.454)\end{array}$ & $\begin{array}{c}1.626 \\
(10.726)\end{array}$ \\
\hline & SMB & $\begin{array}{c}0.885 \\
(6.033)\end{array}$ & $\begin{array}{c}4.288 \\
(11.256)\end{array}$ & $\begin{array}{c}-2.678 \\
(-11.115)\end{array}$ \\
\hline \multirow[t]{4}{*}{ December 1985} & IML_PS & $\begin{array}{c}0.057 \\
(0.555)\end{array}$ & $\begin{array}{c}-0.652 \\
(-2.133)\end{array}$ & $\begin{array}{c}1.893 \\
(4.140)\end{array}$ \\
\hline & $\mathrm{Rm}-\mathrm{Rf}$ & $\begin{array}{c}0.178 \\
(4.023)\end{array}$ & $\begin{array}{c}-0.718 \\
(-3.645)\end{array}$ & $\begin{array}{c}1.113 \\
(6.086)\end{array}$ \\
\hline & HML & $\begin{array}{c}0.268 \\
(7.722)\end{array}$ & $\begin{array}{c}0.825 \\
(5.456)\end{array}$ & $\begin{array}{c}-0.486 \\
(-3.461)\end{array}$ \\
\hline & SMB & $\begin{array}{c}0.384 \\
(10.888)\end{array}$ & $\begin{array}{c}0.853 \\
(9.588)\end{array}$ & $\begin{array}{c}-1.475 \\
(-11.506)\end{array}$ \\
\hline \multirow[t]{4}{*}{ December 1995} & IML_PS & $\begin{array}{c}-1.091 \\
(-11.078)\end{array}$ & $\begin{array}{c}0.960 \\
(3.000)\end{array}$ & $\begin{array}{c}0.765 \\
(7.335)\end{array}$ \\
\hline & $\mathrm{Rm}-\mathrm{Rf}$ & $\begin{array}{l}-1.473 \\
(-9.112)\end{array}$ & $\begin{array}{l}0.876 \\
(5.997)\end{array}$ & $\begin{array}{c}1.963 \\
(12.333)\end{array}$ \\
\hline & HML & $\begin{array}{l}1.106 \\
(8.691)\end{array}$ & $\begin{array}{c}-0.386 \\
(-1.486)\end{array}$ & $\begin{array}{c}-0.472 \\
(-4.899)\end{array}$ \\
\hline & SMB & $\begin{array}{c}1.507 \\
(10.809)\end{array}$ & $\begin{array}{c}-1.266 \\
(-7.125)\end{array}$ & $\begin{array}{c}-0.908 \\
(-8.743)\end{array}$ \\
\hline \multirow[t]{4}{*}{ December 2004} & IML_PS & $\begin{array}{c}-0.032 \\
(-0.150)\end{array}$ & $\begin{array}{c}-2.299 \\
(-5.278)\end{array}$ & $\begin{array}{c}0.739 \\
(4.436)\end{array}$ \\
\hline & $\mathrm{Rm}-\mathrm{Rf}$ & $\begin{array}{c}1.108 \\
(3.813)\end{array}$ & $\begin{array}{c}-1.645 \\
(-6.942)\end{array}$ & $\begin{array}{c}-0.295 \\
(-0.876)\end{array}$ \\
\hline & HML & $\begin{array}{c}0.151 \\
(0.689)\end{array}$ & $\begin{array}{c}1.913 \\
(7.939)\end{array}$ & $\begin{array}{c}0.157 \\
(0.651)\end{array}$ \\
\hline & SMB & $\begin{array}{c}0.832 \\
(5.350)\end{array}$ & $\begin{array}{c}2.332 \\
(7.153)\end{array}$ & $\begin{array}{c}-0.826 \\
(-3.304)\end{array}$ \\
\hline
\end{tabular}




\section{Table A-II: continued.}

Panel C: Distribution of the conditional liquidity premium

\begin{tabular}{lcccc} 
& & \multicolumn{2}{c}{ Interquantile Range } \\
\cline { 5 - 5 } & Mean & Std. Dev. & $25 \%$ & $75 \%$ \\
\hline With conditional forecast of factor risk premia: & & & & \\
Conditional Liquidity Risk Premium (\%, annual) & 1.712 & 4.960 & 0.000 & 4.487 \\
Liquidity Risk Premium / Total Risk Premium (\%) & 38.661 & 29.163 & 13.474 & 65.424 \\
& & & & \\
& & & & \\
With unconditional forecast of factor risk premia: & & & \\
Conditional Liquidity Risk Premium (\%, annual) & 2.710 & 2.919 & 1.345 & 4.780 \\
Liquidity Risk Premium / Total Risk Premium (\%) & 47.711 & 26.195 & 31.178 & 70.851 \\
\hline
\end{tabular}




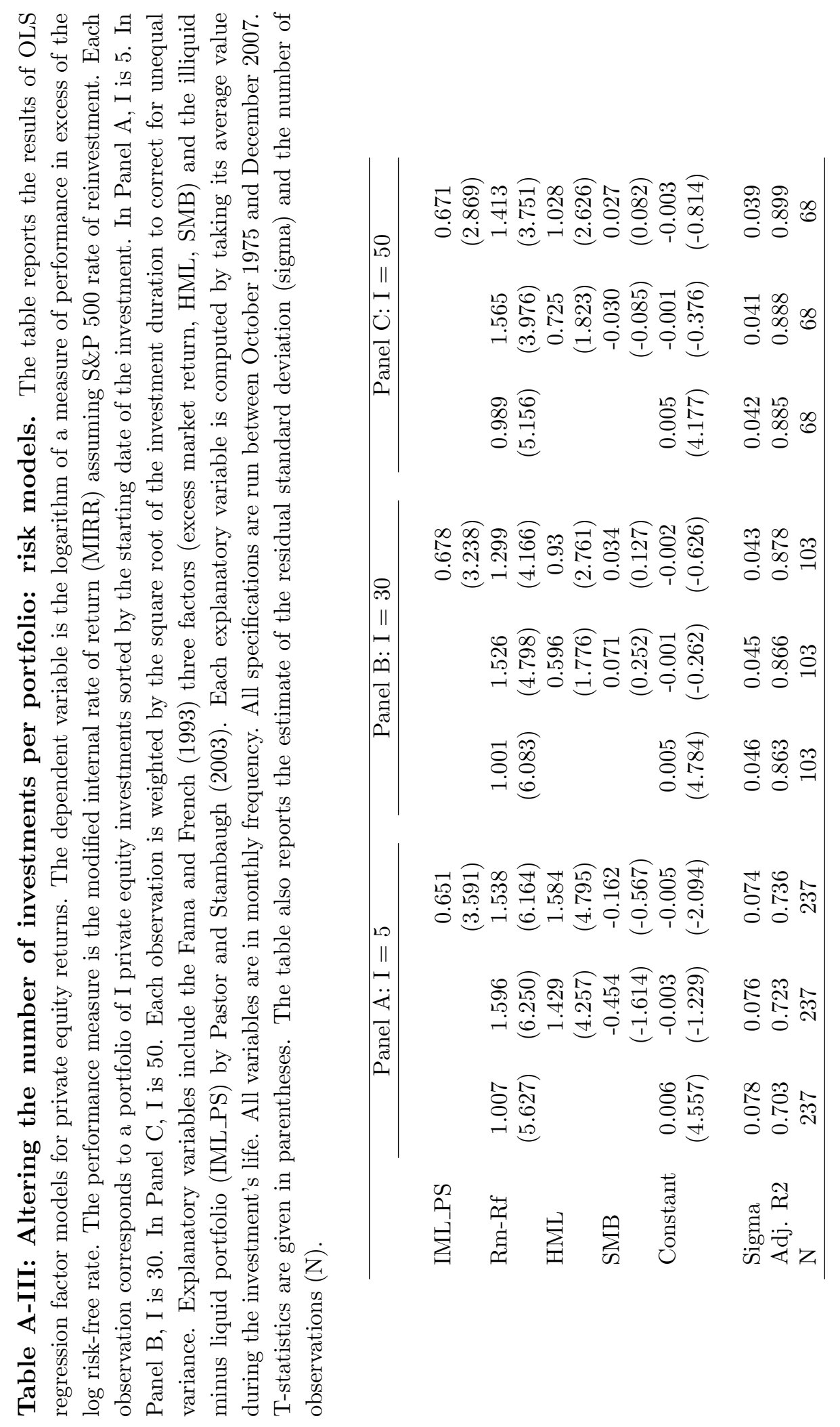




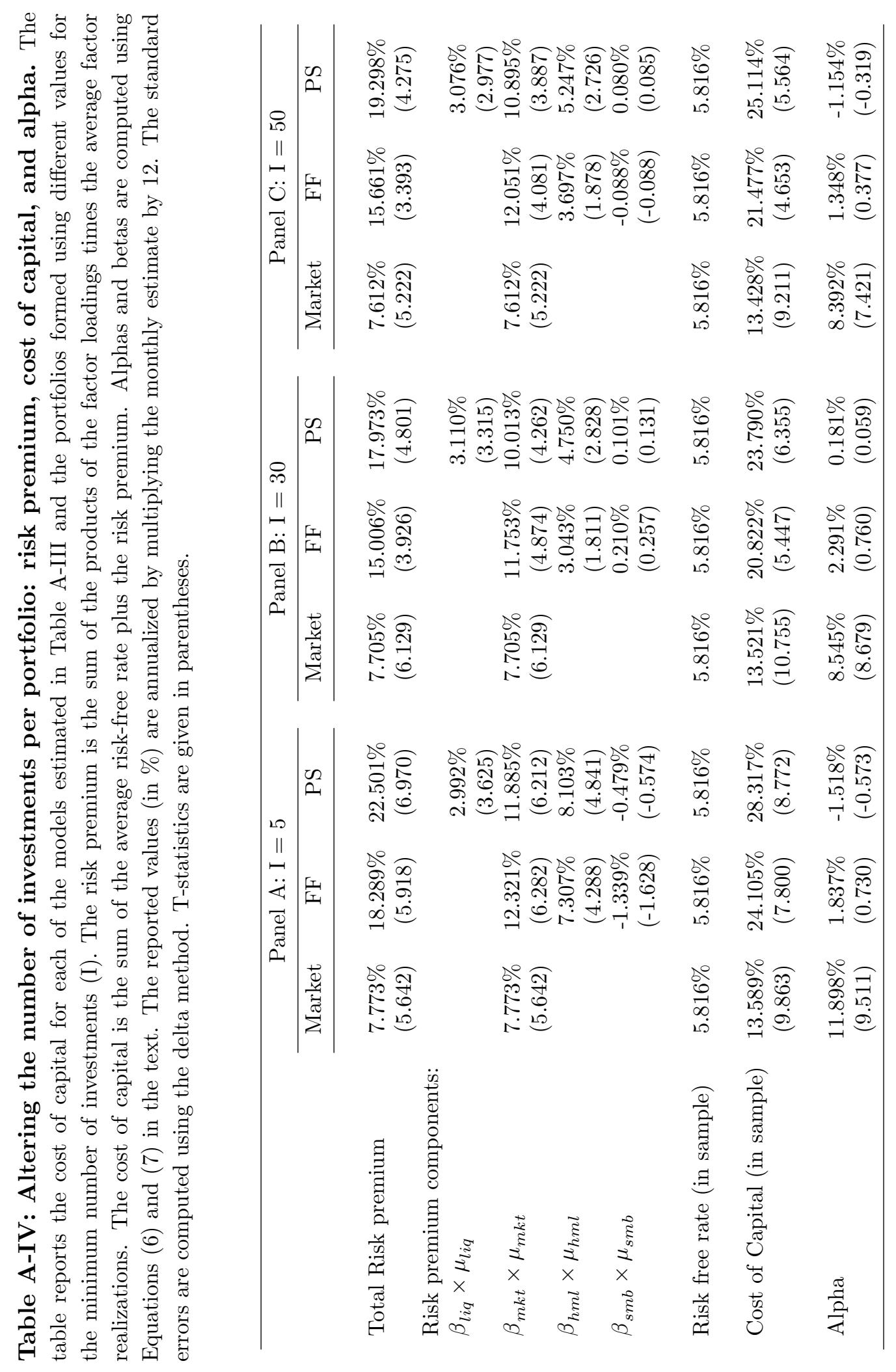




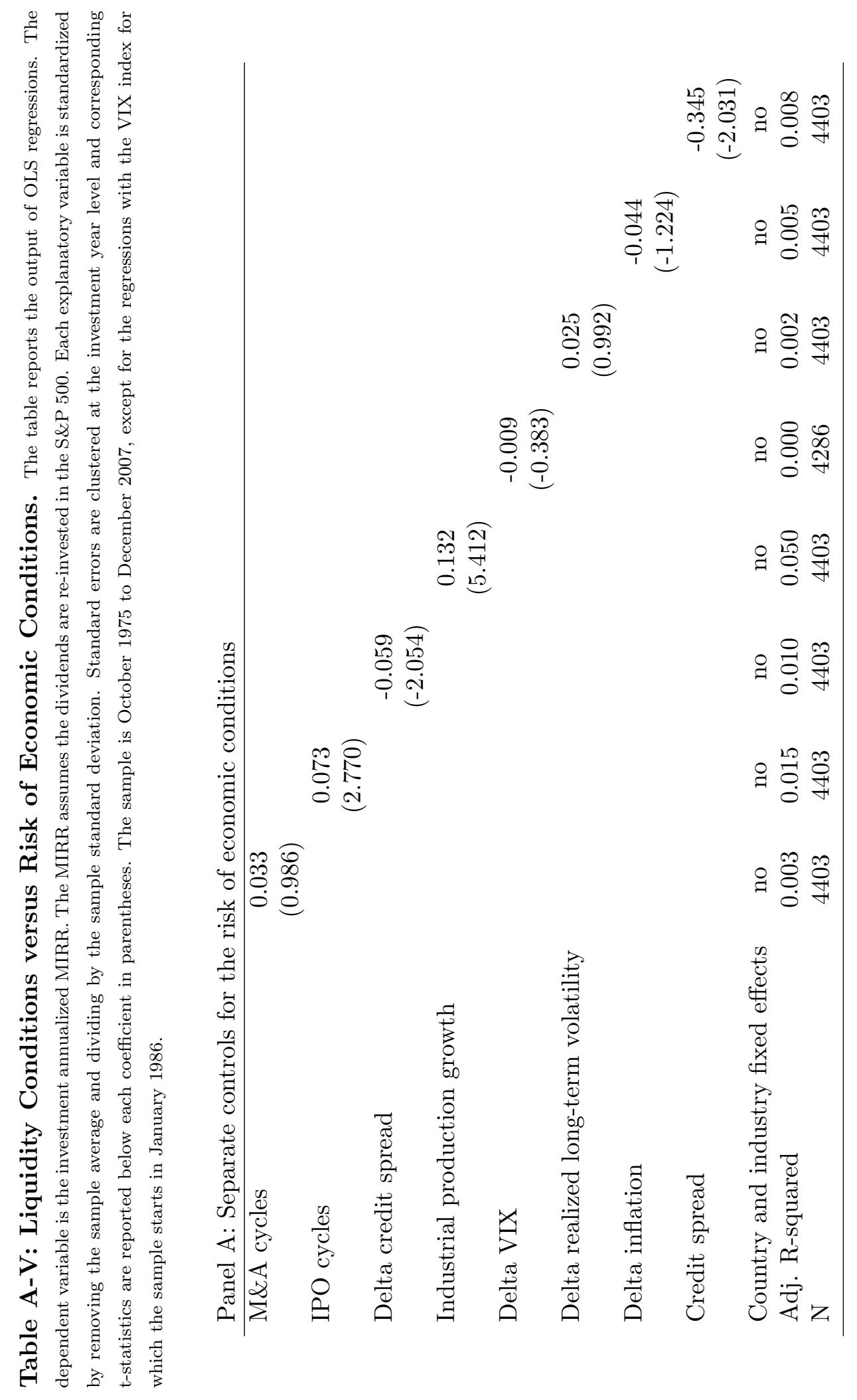




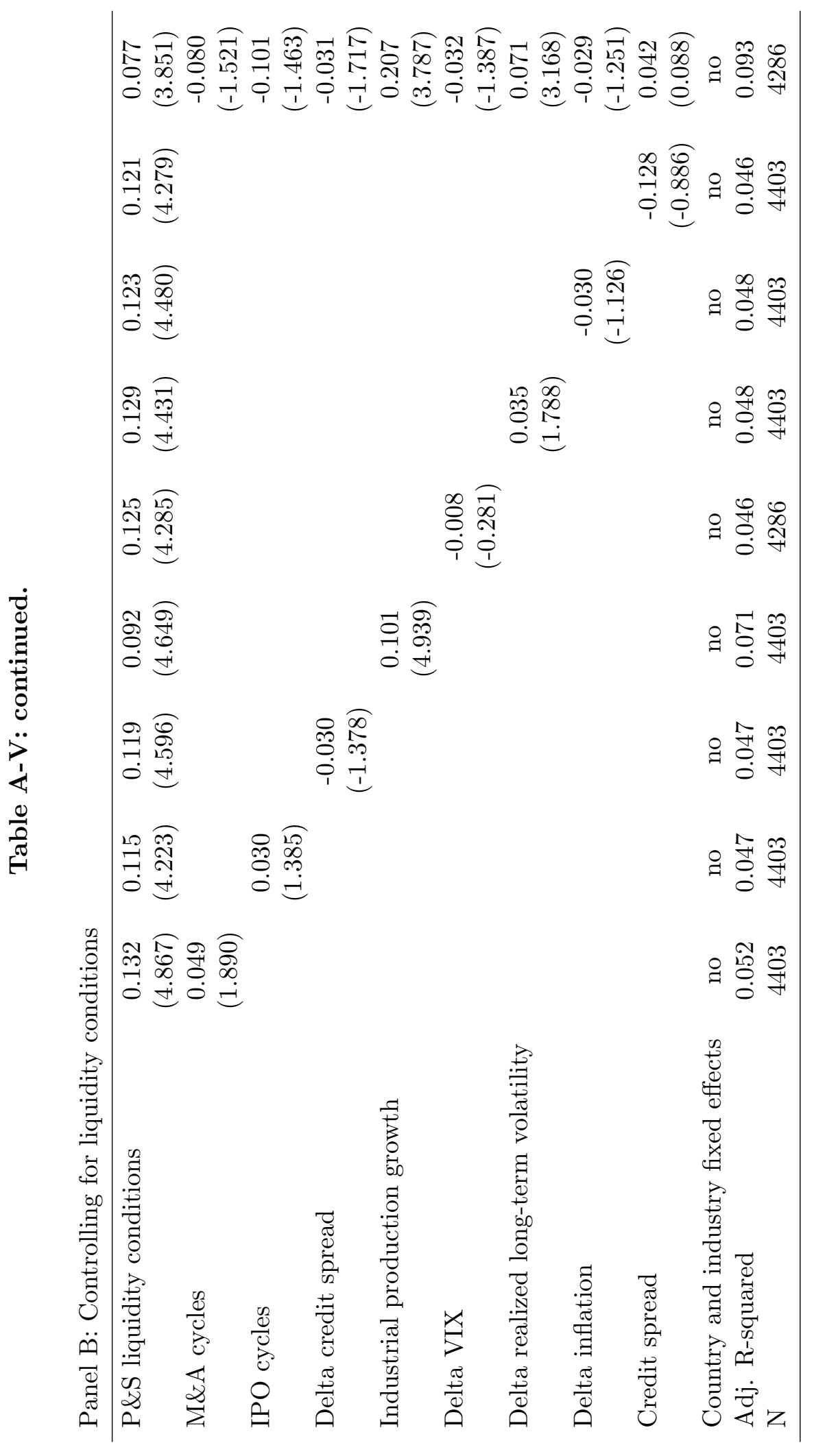




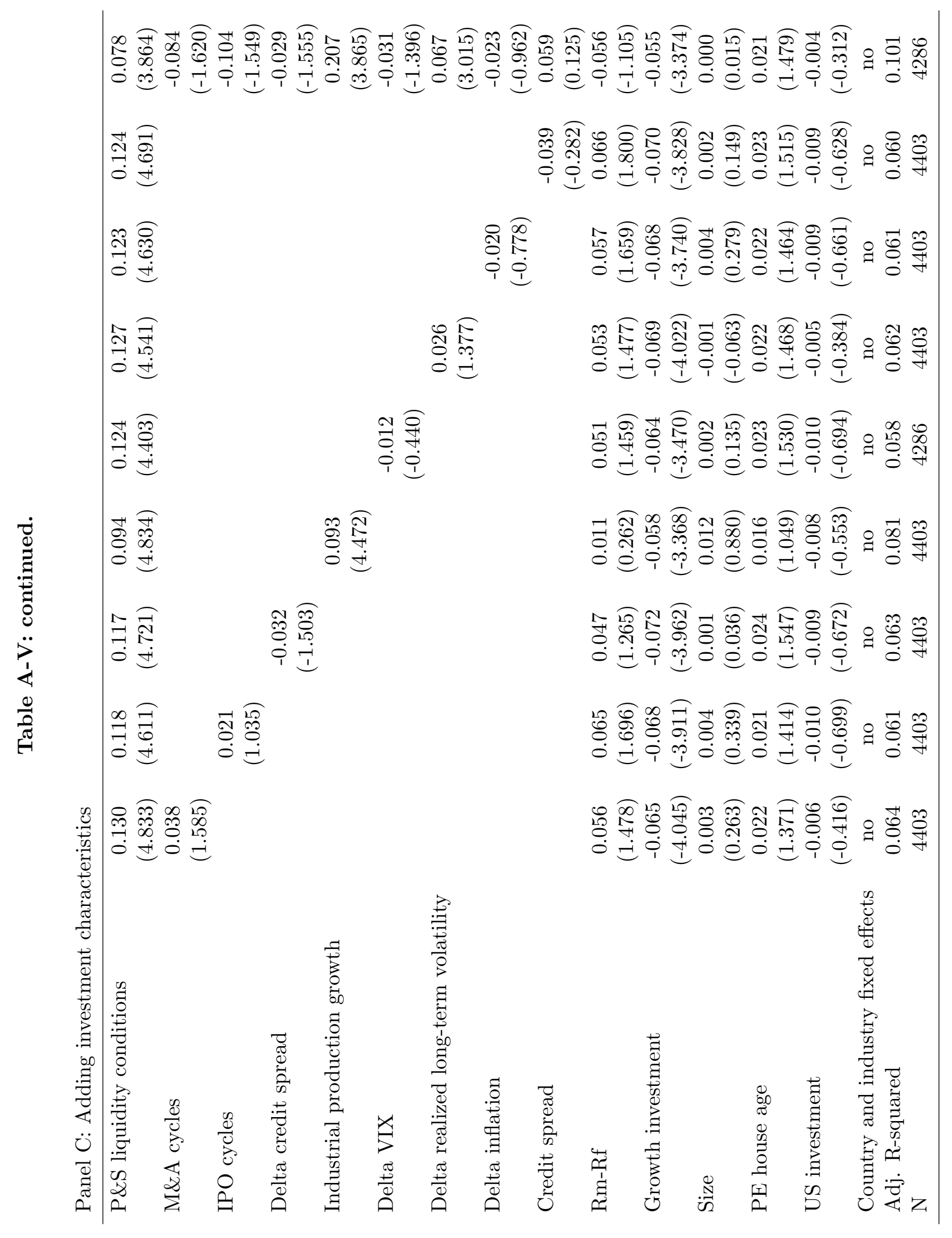




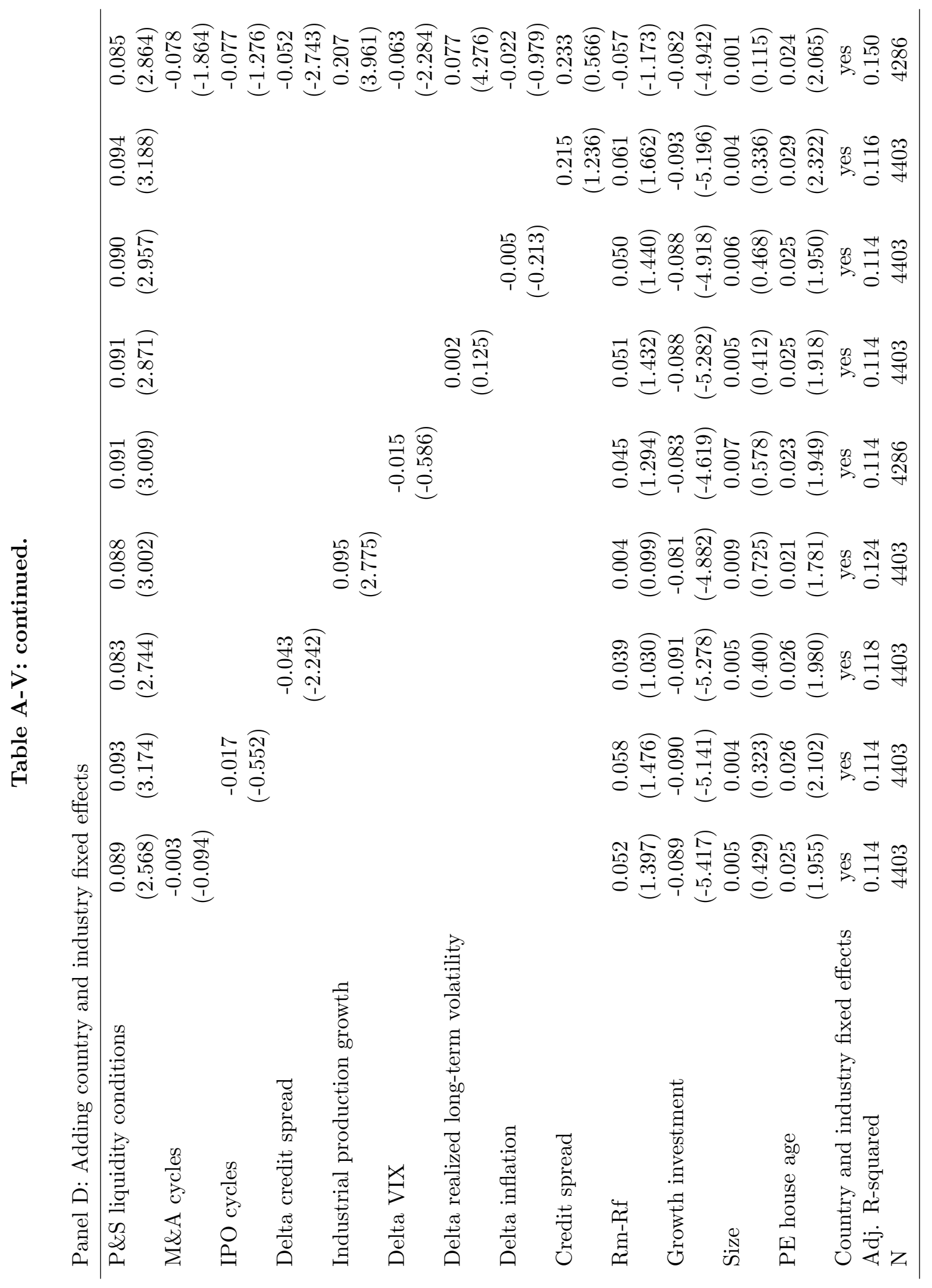




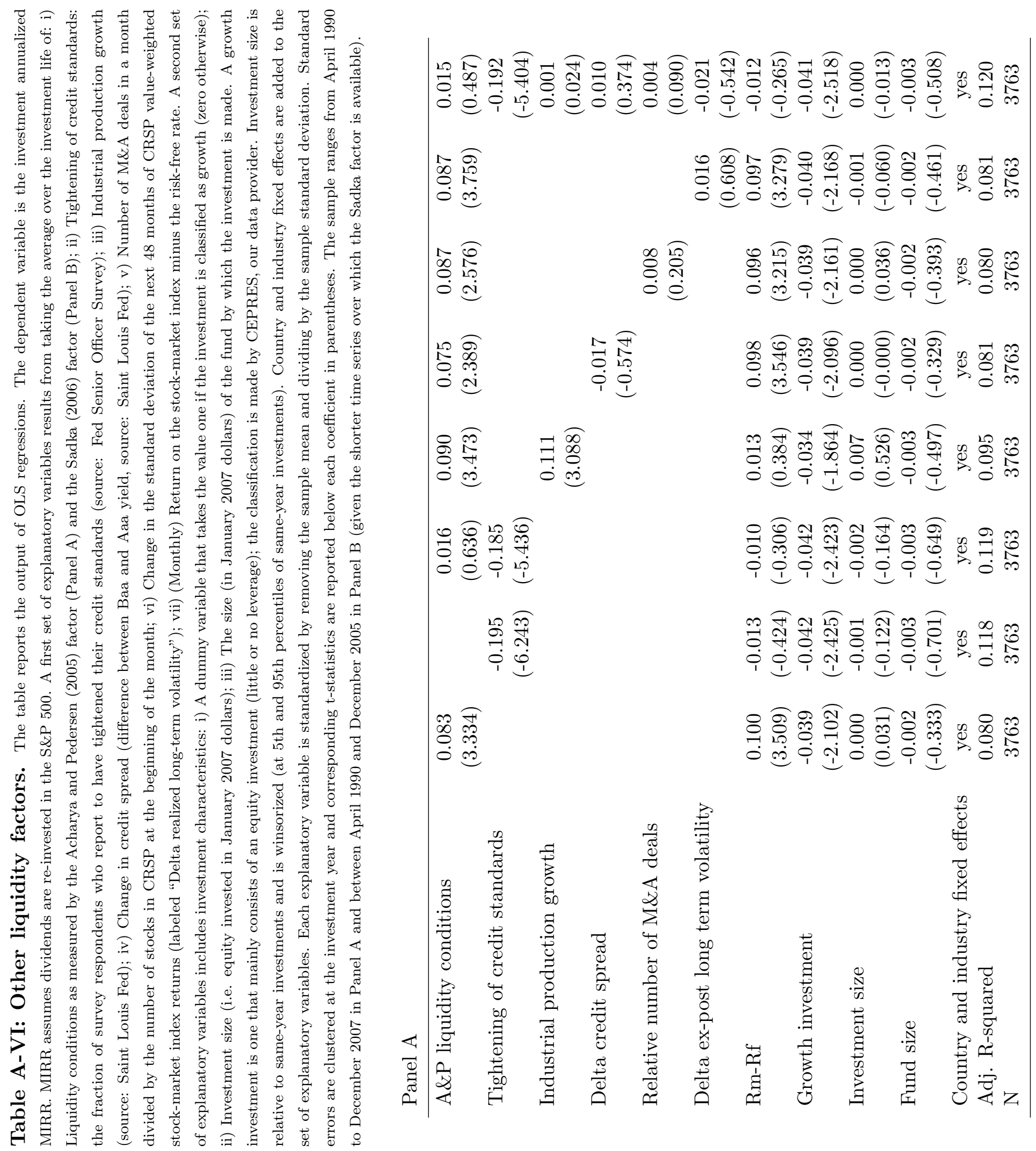




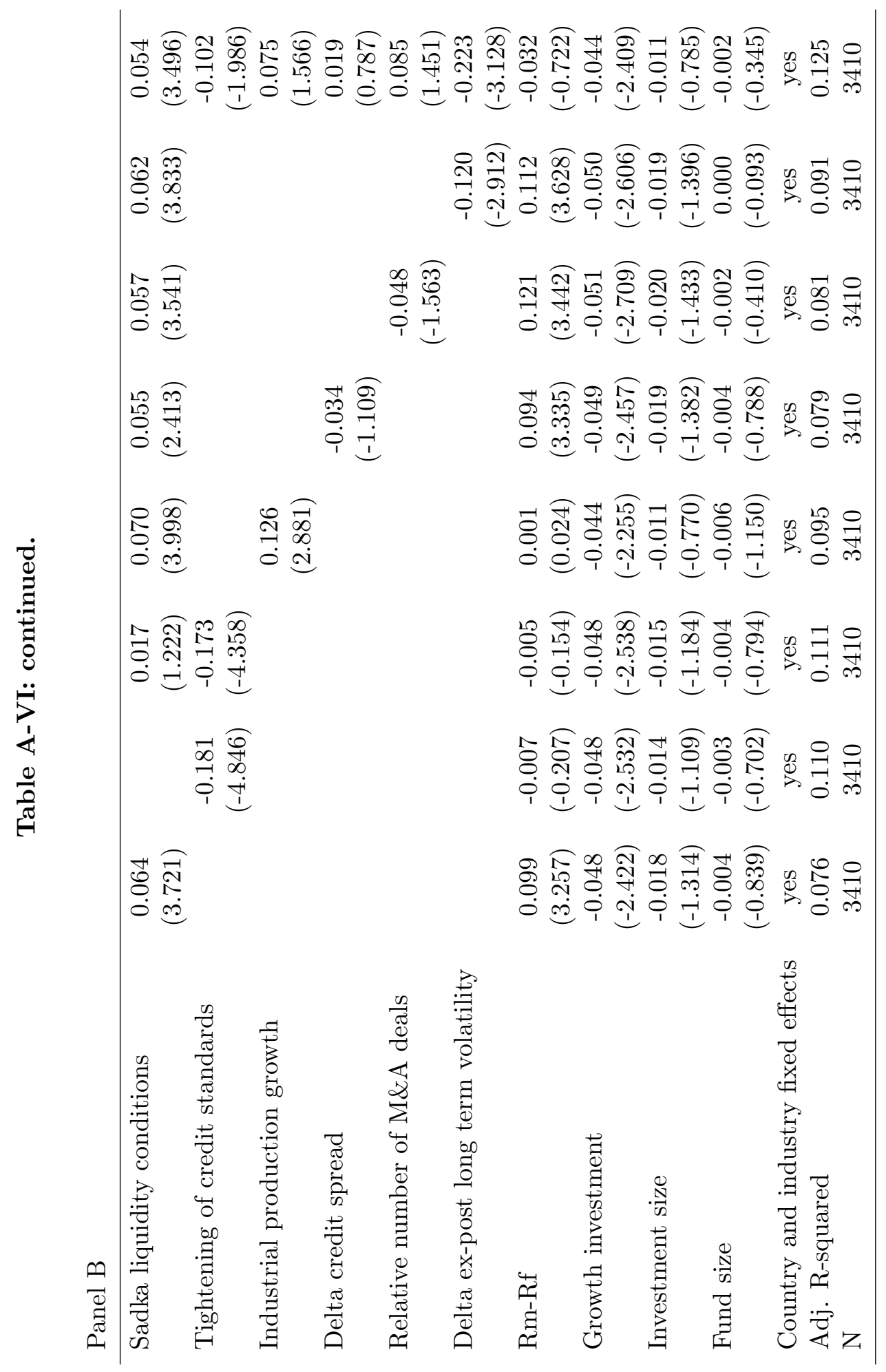




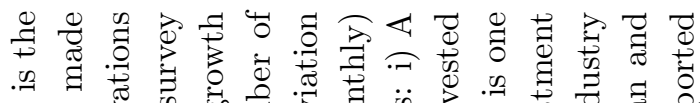

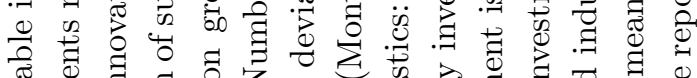

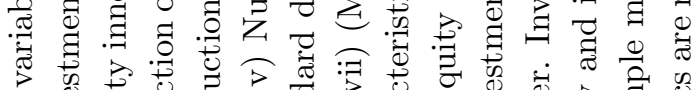
$>$ की

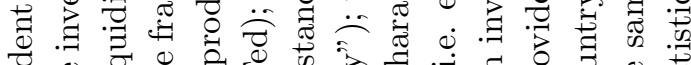

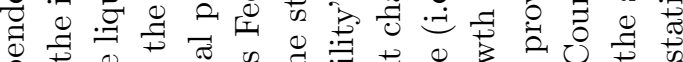

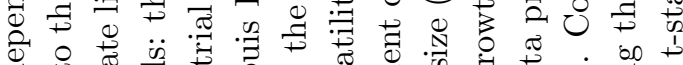

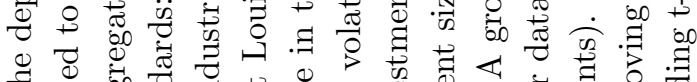

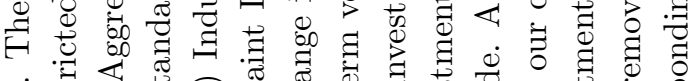

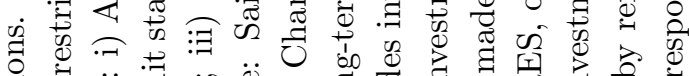

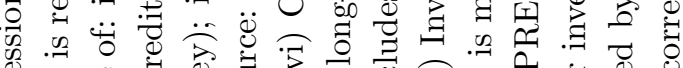

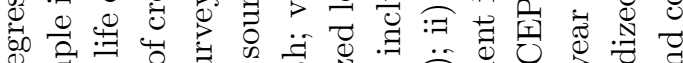

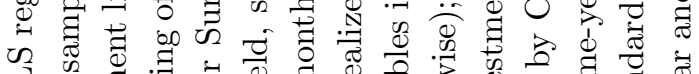
0 욤

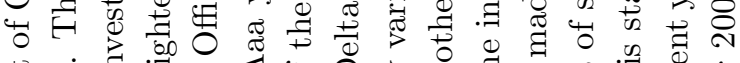

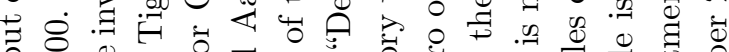

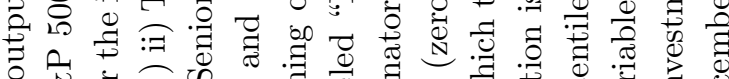

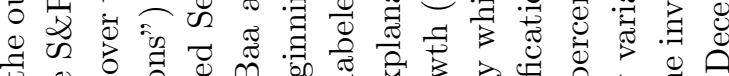

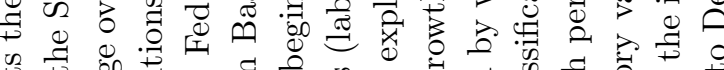

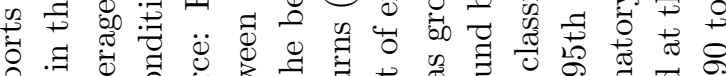

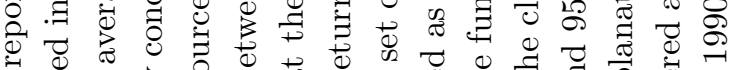

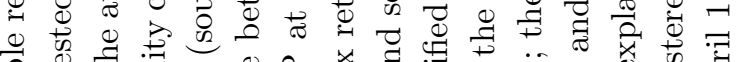

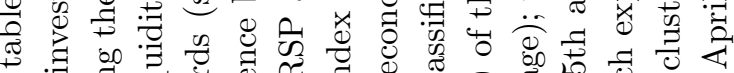

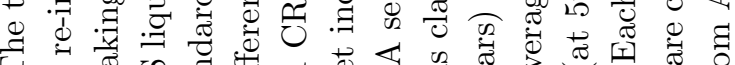
$\exists$ 两

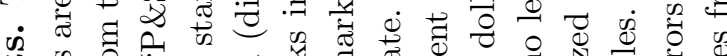

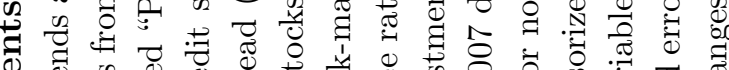

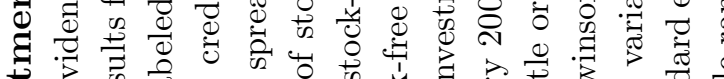
पे

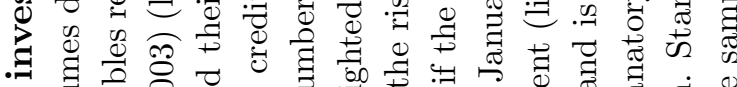

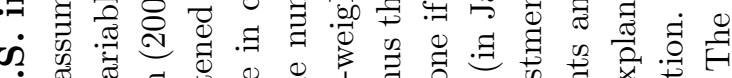

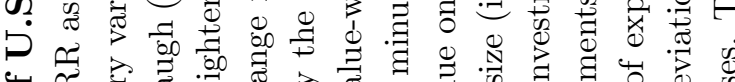

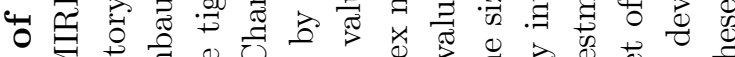

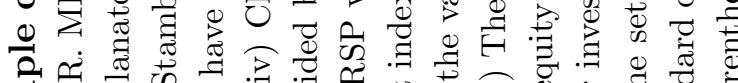

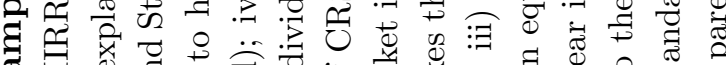

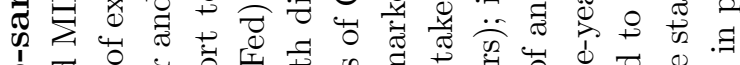

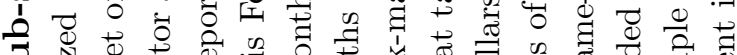
जी:

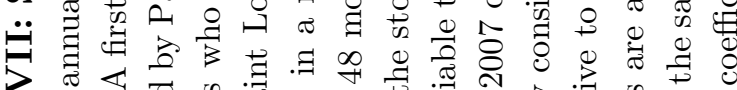

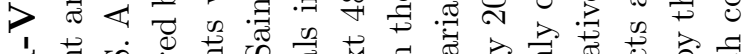

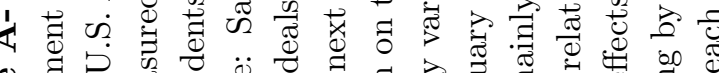

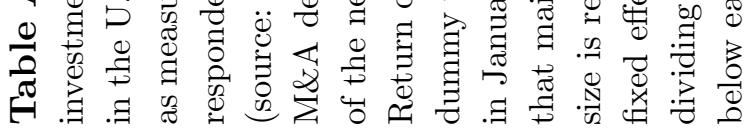

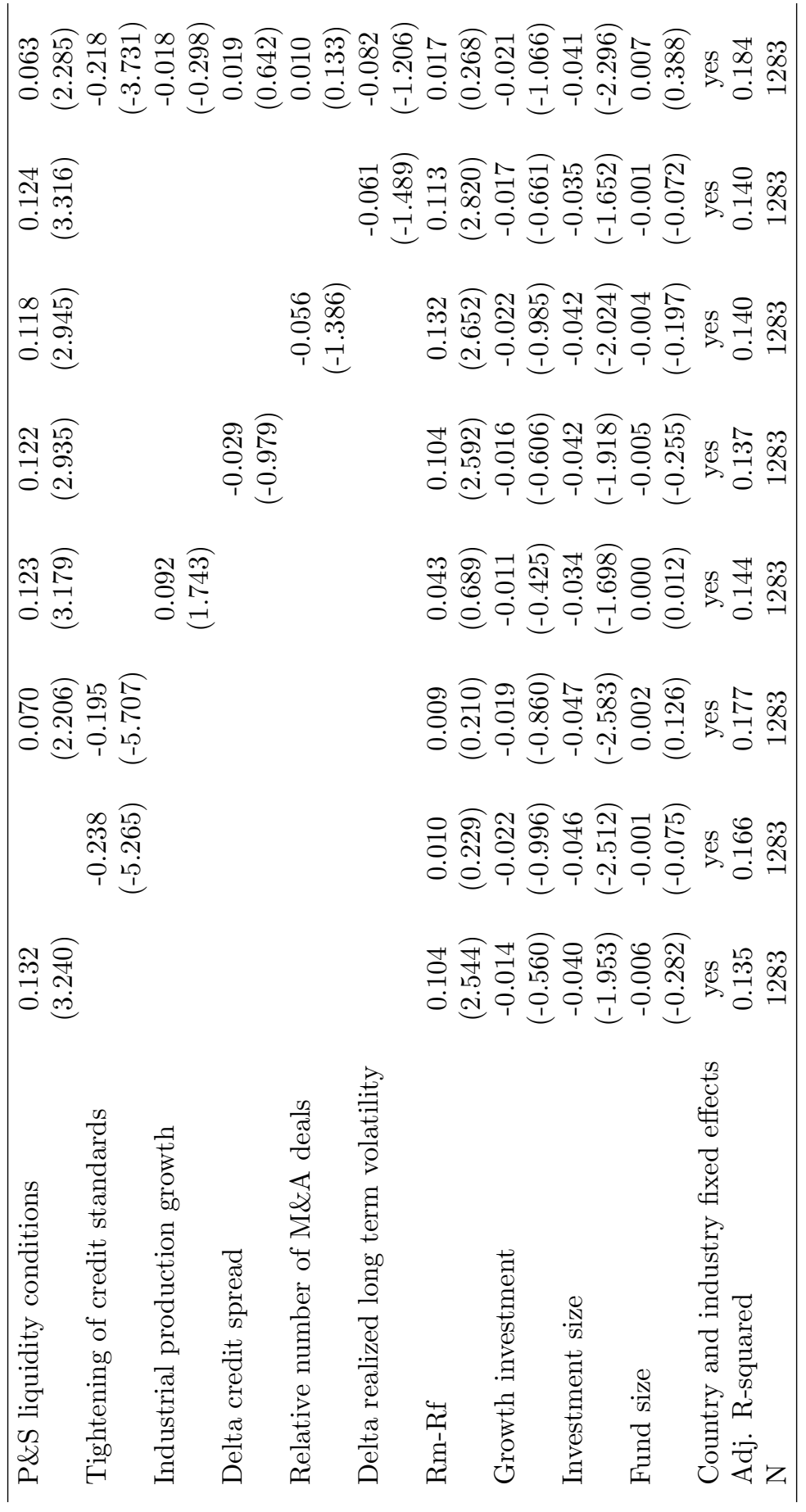




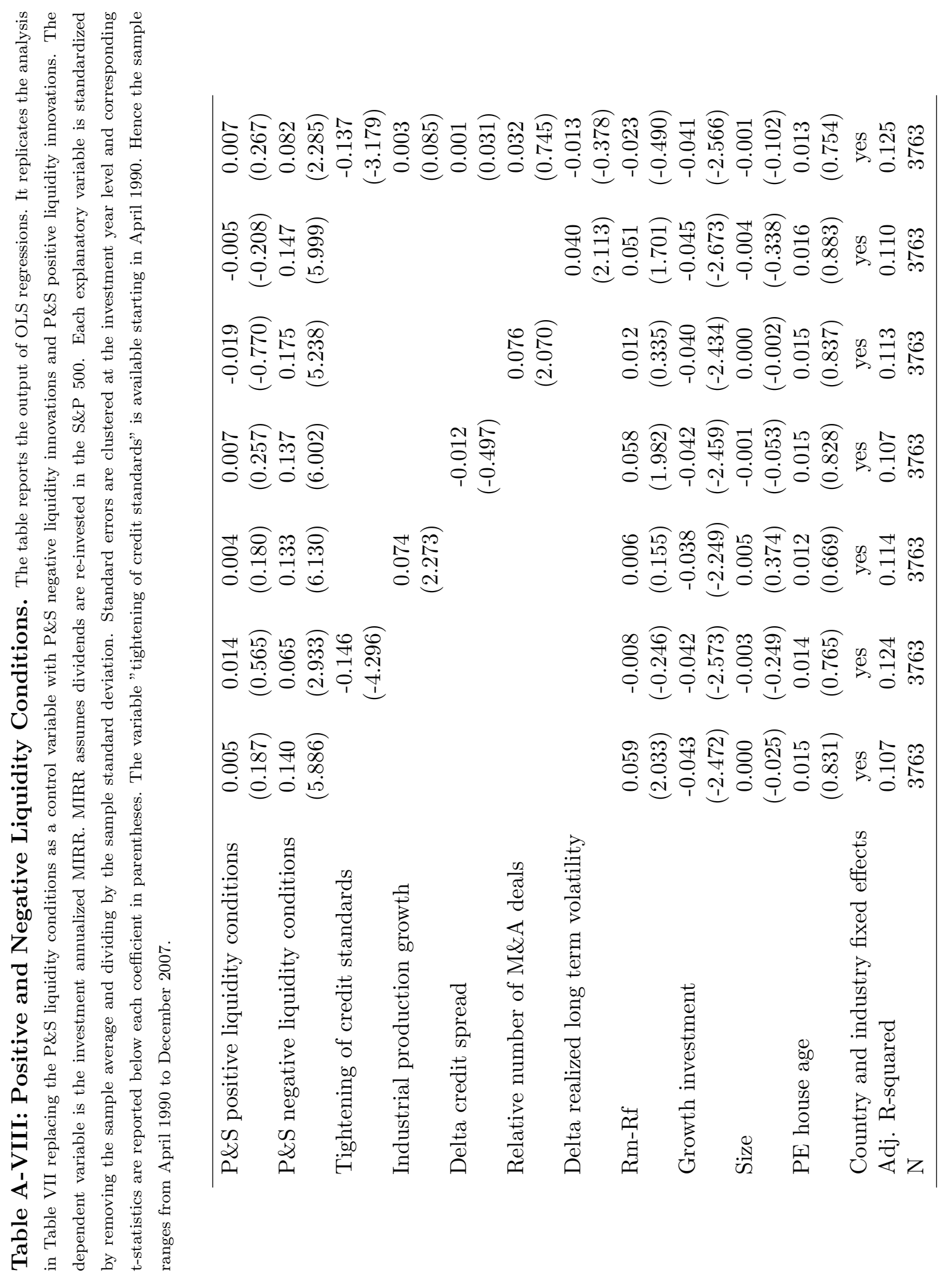




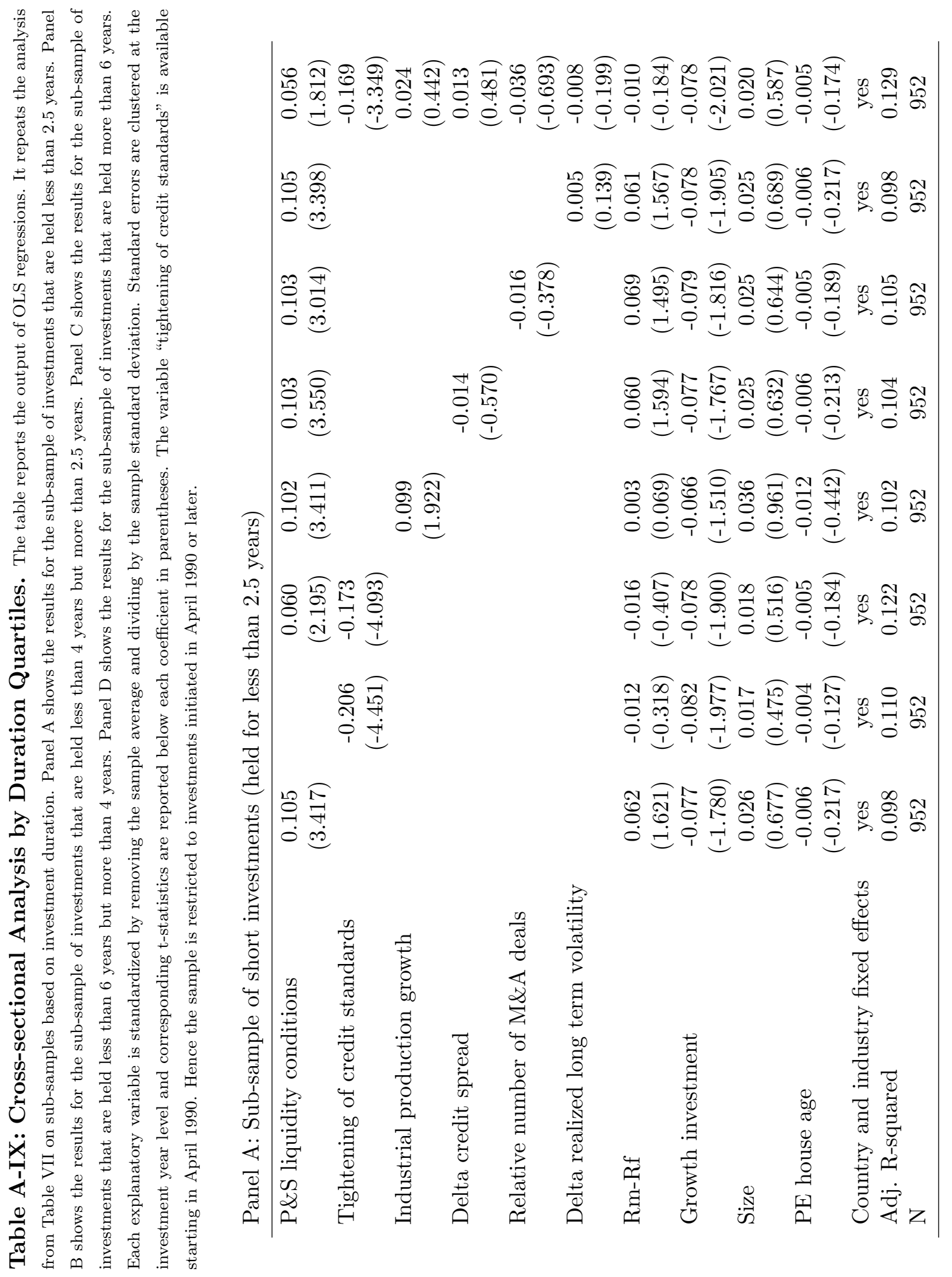




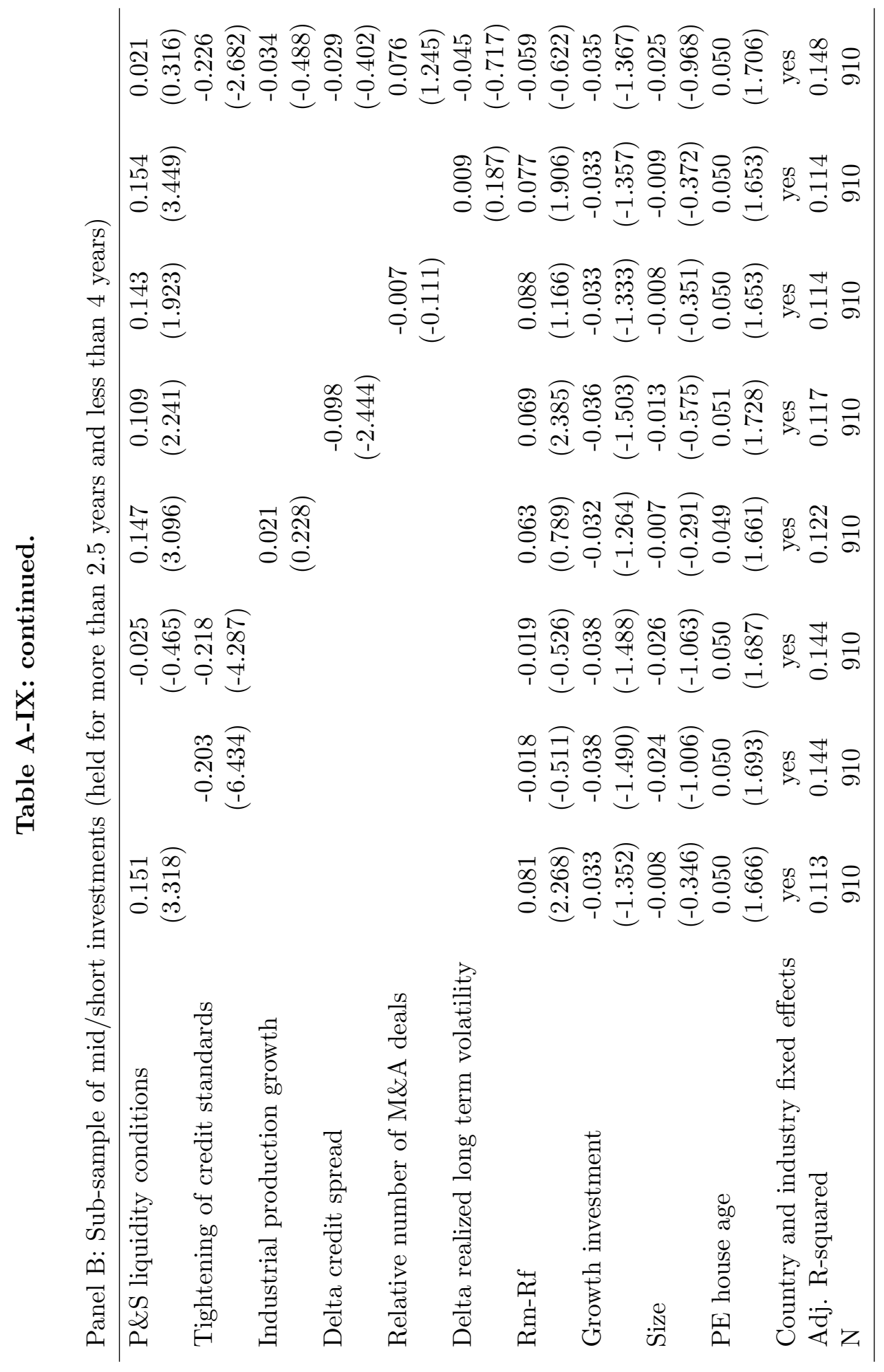




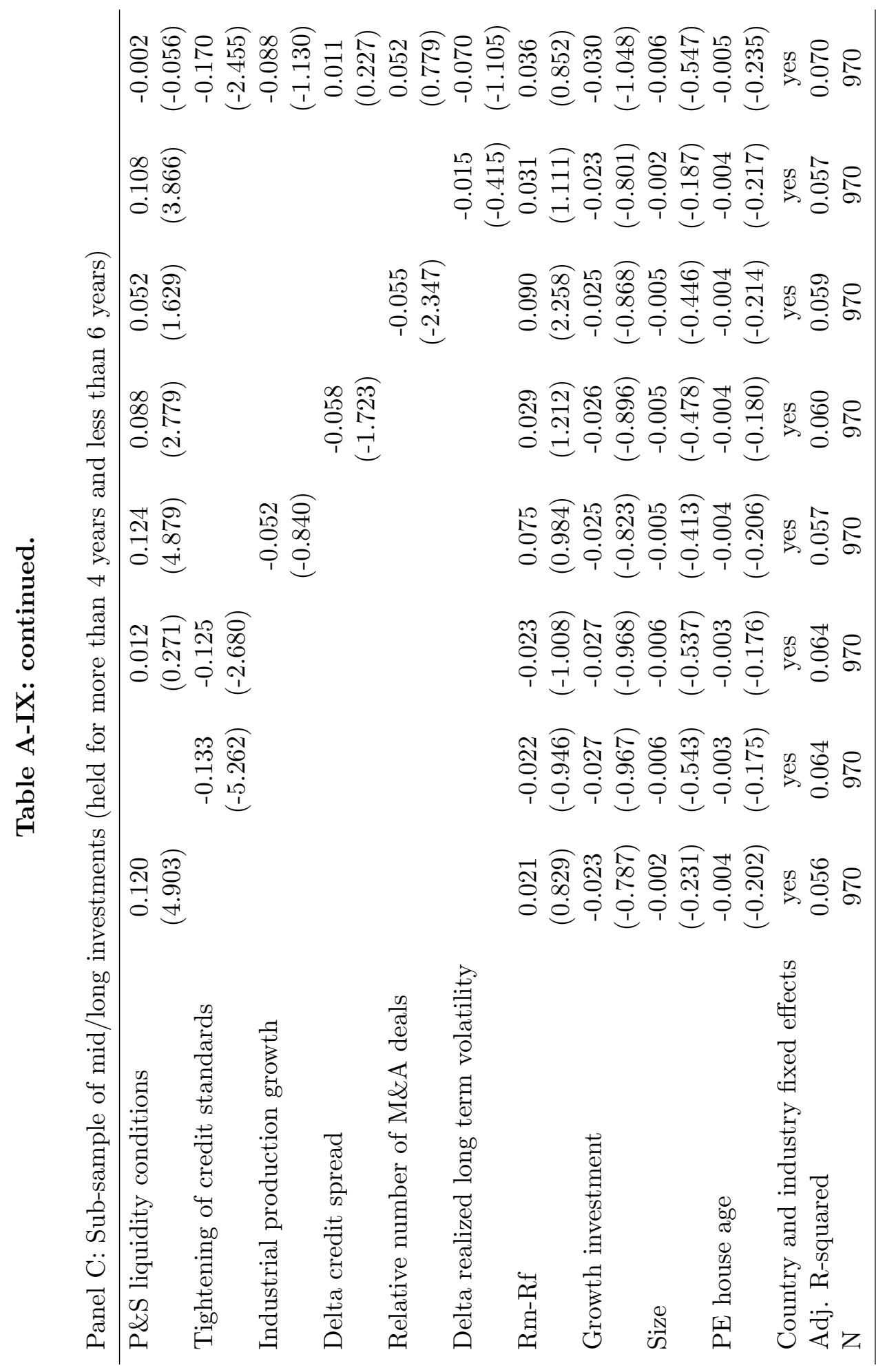




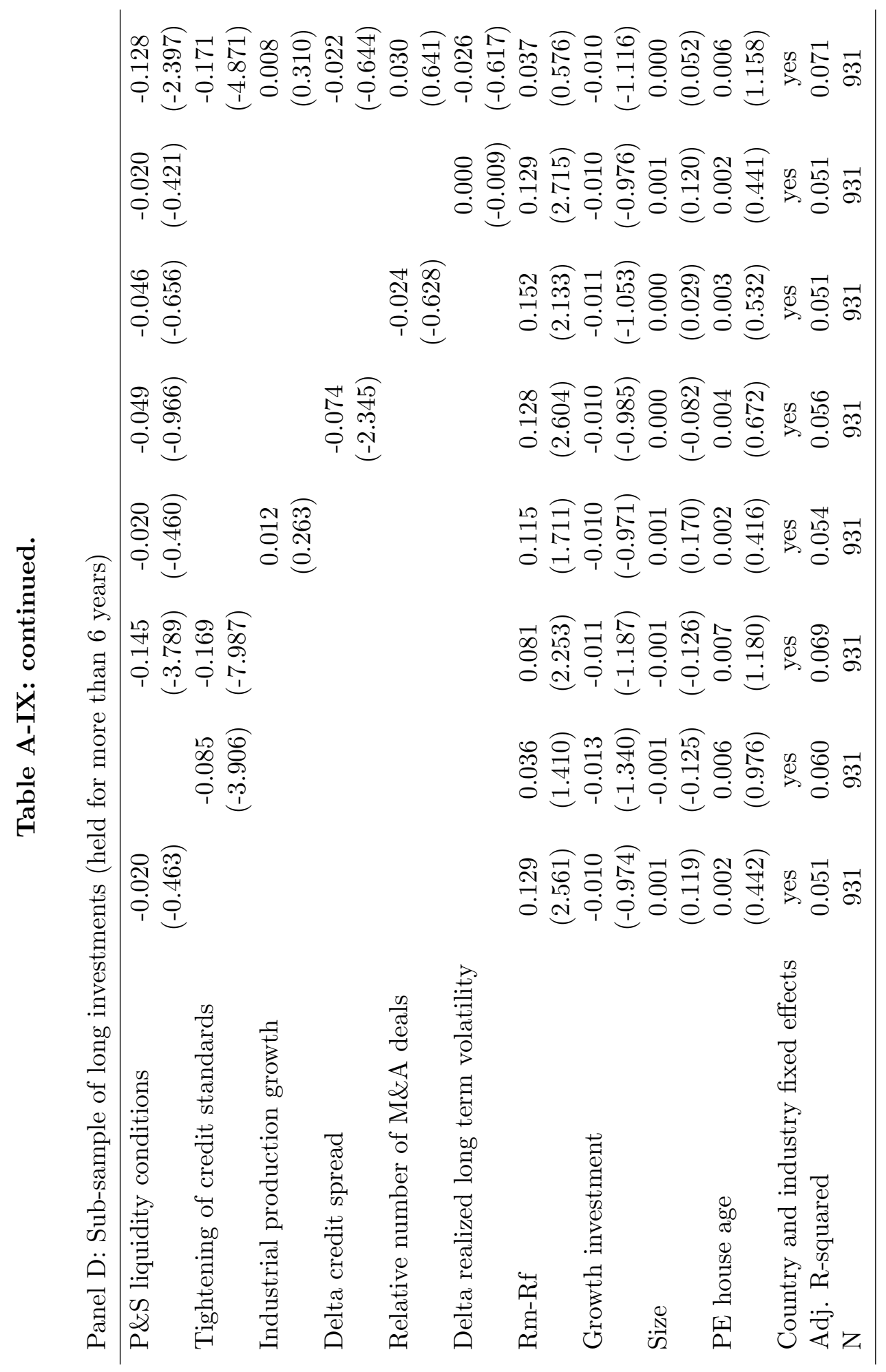




\section{Notes}

${ }^{1}$ In principle, one should convert the estimated loadings from the logarithmic representation of returns to the representation in levels using equation (7). However, the difference between the two quantities is negligible. So, for simplicity, we use the estimates from the equation in logs.

${ }^{2}$ We use a forty-eight month measurement window for the factor realizations to match the average life of a private equity investment.

${ }^{3}$ Note also that the average conditional liquidity risk premium differs from the $3 \%$ estimate of the unconditional liquidity risk premium that we report in the main analysis. The fact that the mean of the conditional premium does not necessarily equal the product of the unconditional beta time the unconditional factor risk premium has been documented in the literature. The two quantities are different whenever the covariance between the conditional beta and the conditional factor risk premium is not zero (see, e.g., Lewellen and Nagel (2006)). 